\title{
Neuropeptide Y Suppresses Anorexigenic Output from the Ventromedial Nucleus of the Hypothalamus
}

\author{
Melissa J. S. Chee, ${ }^{1,2}$ Martin G. Myers Jr, ${ }^{3}$ Christopher J. Price, ${ }^{2}$ and William F. Colmers ${ }^{1,2}$ \\ ${ }^{1}$ Centre for Neuroscience and 2Department of Pharmacology, University of Alberta, Edmonton, Alberta T6G 2H7, Canada, and ${ }^{3}$ Department of Molecular \\ and Integrative Physiology, University of Michigan, Ann Arbor, Michigan 48109
}

Output from the hypothalamic ventromedial nucleus (VMN) is anorexigenic and is supported by the excitatory actions of leptin. The VMN is also highly sensitive to the orexigenic actions of Neuropeptide Y (NPY). We report that NPY robustly inhibits VMN neurons by hyperpolarizing them and decreasing their ability to fire action potentials. This action was mediated by $\mathrm{Y}_{1}$ receptors coupled to the activation of GIRKs (G-protein-coupled inwardly rectifying potassium channels). Approximately $80 \%$ of VMN neurons expressing leptin receptors were sensitive to the actions of NPY, whereas $75 \%$ of NPY-sensitive neurons in VMN also responded to glucose by being uniformly inhibited by elevations in glucose. Interestingly, only 36\% of NPY-sensitive, leptin receptor b-expressing neurons were also glucosensitive. We suggest that NPY inhibits VMN neurons that are excited by leptin, thereby arresting the anorexigenic tone exerted by VMN neurons. The results further suggest a dynamic interplay between anorexigenic and orexigenic neuromodulators within the VMN to directly affect energy balance.

\section{Introduction}

The ventromedial hypothalamus (VMH) has been recognized to play a crucial role in energy balance regulation since Hetherington and Ranson (1940) demonstrated that bilateral electrolytic lesions of the rat VMH resulted in hyperphagia and obesity. More recently, the specific loss of neurons within the ventromedial nucleus (VMN) of the VMH in steroidogenic factor 1 (SF-1) knock-out (KO) mice was shown to also result in the development of obesity (Majdic et al., 2002). Together, these and many other experiments suggest that ongoing activity of VMN neuronal output inhibits feeding behavior (King, 2006); this activity is facilitated in part by the excitatory action of leptin (Dhillon et al., 2006). The VMN primarily contains excitatory (glutamatergic) neurons (Collin et al., 2003) that may interact with neurons in other brain areas important for energy balance, including the arcuate nucleus of the hypothalamus (ARC), brainstem, amygdala, and ventral tegmental area (Saper et al., 1976; Canteras et al., 1994; Sternson et al., 2005).

Interestingly, the VMN richly expresses receptors for orexigenic peptides. In particular, the VMN is highly sensitive to the orexigenic actions of Neuropeptide Y (NPY) (Stanley et al., 1993; Bouali et al., 1995; Jolicoeur et al., 1995). Administration of NPY intracerebroventricularly (Clark et al., 1984; Kalra et al., 1991) or

Received Aug. 17, 2009; revised Jan. 18, 2010; accepted Jan. 22, 2010.

This work was supported by Canadian Institute for Health Research (CIHR) Grant MT10250 and CIHR Team on the Neurobiology of Obesity Grant OTG 88592 (W.F.C.) and by National Institutes of Health Grant R01 DK078056 (M.G.M.). M.J.S.C. was supported by a Queen Elizabeth II scholarship, a Hotchkiss Brain Institute studentship, and a studentship from the Alberta Heritage Foundation for Medical Research (AHFMR).W.F.C. is a Medical Scientist of the AHFMR. We thank Dr. Rebecca Leshan for her technical assistance and Dr. Annette Beck-Sickinger for her gift of the selective NPY receptor agonists and antagonists.

Correspondence should be addressed to William F. Colmers, Department of Pharmacology, University of Alberta, 9-36 Medical Science Building, Edmonton, AB T6G 2H7, Canada. E-mail: william.colmers@ualberta.ca.

DOI:10.1523/JNEUROSCI.4031-09.2010

Copyright $\odot 2010$ the authors $\quad 0270-6474 / 10 / 303380-11 \$ 15.00 / 0$ by direct microinjection into specific hypothalamic sites (Stanley et al., 1993) can stimulate food intake. The VMN is among one of the most sensitive targets for NPY action (Stanley et al., 1993; Bouali et al., 1995; Jolicoeur et al., 1995). In extracellular recordings made in vitro, NPY reduced the firing activity of VMN neurons (Davidowa et al., 2002) by the activation of $Y_{1}$ receptors (Kumarnsit et al., 2003). However, little is known about the mechanisms underlying the actions of NPY receptor activation in the VMN.

In this study, we tested the hypothesis that the orexigenic actions of NPY are mediated by its direct inhibitory effects on VMN neurons that express leptin receptors. We described the direct and indirect synaptic mechanisms by which NPY can modulate the activity of VMN neurons. Furthermore, we also described the convergence of metabolic actions on VMN neurons. Our findings support the idea that the orexigenic actions of NPY within the VMN result from the suppression of ongoing anorexigenic VMN neural output.

\section{Materials and Methods}

\section{Transgenic mice}

We previously reported the generation of mice that contain an IRESdriven second cistron encoding cre recombinase "knocked in" to the $3^{\prime}$-untranslated region of the leptin receptor (LepRb)-specific exon of Lepr (Leshan et al., 2006). Hence, in Lepr ${ }^{\text {cre }}$ mice, the cre coding sequence is part of the LepRb-specific mRNA such that its expression is restricted to LepRb-expressing neurons. To reliably identify LepRb-expressing neurons, we crossed the Lepr ${ }^{\text {cre }}$ mice with Gt(ROSA)26Sor ${ }^{\text {tm2Sho }}$ (ROSA ${ }^{E G F P}$ ) mice from The Jackson Laboratory. This line has been engineered such that cre-mediated deletion of a floxed transcription-blocking Neo cassette results in the expression of enhanced green fluorescent protein (EGFP) from the ubiquitously expressed ROSA26 locus (Mao et al., 1999). Since IRES-mediated cre expression is modest, both alleles were bred to homozygosity (Lepr ${ }^{\text {cre/cre }} ; \operatorname{Ros}^{\text {EGFP/EGFP }}$, also known as 


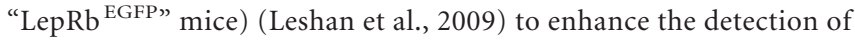
LepRb neurons by EGFP expression.

\section{Slice preparation}

All animal procedures used in this study were previously approved by the Health Sciences Animal Welfare Committee at the University of Alberta, in accordance with guidelines of the Canadian Council on Animal Care. Male C57BL/6 (4-6 weeks of age) or LepRb ${ }^{\text {EGFP }}$ mice (5-6 weeks of age) were decapitated, their brains rapidly removed, and then immediately submerged in a cold $\left(4^{\circ} \mathrm{C}\right)$, carbogenated $\left(95 \% \mathrm{O}_{2}, 5 \% \mathrm{CO}_{2}\right)$ slicing solution containing the following (in $\mathrm{mM}$ ): $118 \mathrm{NaCl}, 3 \mathrm{KCl}, 1.3 \mathrm{MgSO}_{4}$, $1.4 \mathrm{NaH}_{2} \mathrm{PO}_{4}, 5 \mathrm{MgCl}_{2}, 7$ glucose, 3 sucrose, $26 \mathrm{NaHCO}_{3}, 2 \mathrm{CaCl}_{2}(300-$ $302 \mathrm{mOsm} / \mathrm{L}$ ). Coronal slices ( $250 \mu \mathrm{m}$ thick) containing the VMN were sectioned from a brain block using a vibrating slicer (Slicer HR2; Sigmann Elektronik), incubated for $1 \mathrm{~h}$ at $34^{\circ} \mathrm{C}$ in a carbogenated artificial CSF (aCSF) containing the following (in $\mathrm{mm}$ ): $124 \mathrm{NaCl}, 3 \mathrm{KCl}, 1.3$ $\mathrm{MgSO}_{4}, 1.4 \mathrm{NaH}_{2} \mathrm{PO}_{4}, 2.5$ glucose, 7.5 sucrose, $26 \mathrm{NaHCO}_{3}, 2.5 \mathrm{CaCl}_{2}$ $(300-302 \mathrm{mOsm} / \mathrm{L})$, and then maintained at room temperature $\left(23^{\circ} \mathrm{C}\right)$ for the remainder of the day until needed for patch-clamp recordings.

\section{Patch-clamp recording}

Slices were held submerged by a platinum and polyester fiber "harp" in a recording chamber that is attached to a fixed stage and viewed with a movable upright microscope (Axioskop FS2; Carl Zeiss). The slices were equilibrated for $20 \mathrm{~min}$ in the recording chamber under a continuous flow $(2.5-3.5 \mathrm{ml} / \mathrm{min})$ of warm $\left(32-33^{\circ} \mathrm{C}\right)$ aCSF before initiating recordings. Individual neurons from the VMN, which appeared under $5 \times$ (low) magnification as dark gray oval areas located on either side of the ventral edge of the third ventricle, were visualized with a $60 \times$ waterimmersion objective (LUMPlan Fl $60 \times / 0.50 \mathrm{~W}$; Olympus) using infrared-differential interference contrast microscopy. Cells expressing green fluorescence in LepRb ${ }^{\text {EGFP }}$ animals were identified using epifluorescence illumination (excitation, 450-490 nm; emission, $515 \mathrm{~nm}$; Chroma). Using a four-axis motorized micromanipulator (MX7600; Siskiyou), individual cells were approached with a thin-walled glass pipette (TW150F; World Precision Instruments) pulled on a two-stage microelectrode puller (PP-83; Narishige). Each pipette was backfilled with an internal solution containing the following (in $\mathrm{mM}$ ): $137 \mathrm{~K}$-gluconate, $2 \mathrm{KCl}, 5$ HEPES, 5 MgATP, 0.3 NaGTP, 5 EGTA, 8 creatine, and 0.1\% Neurobiotin, adjusted to $\mathrm{pH} 7.25$ with $\mathrm{KOH}$ (296-298 mOsm/L), to yield tip resistances of 5-6 M $\Omega$. Leptin recordings were performed with an internal solution containing the following (in $\mathrm{mM}$ ): $126 \mathrm{~K}$-gluconate, 10 HEPES, $4 \mathrm{KCl}$, 5 MgATP, $0.3 \mathrm{NaGTP}$, and $0.15 \%$ Neurobiotin, adjusted to $\mathrm{pH} 7.25$ with $\mathrm{KOH}(280 \mathrm{mOsm} / \mathrm{L})$. Visualized-patch whole-cell recordings were obtained from patch pipettes connected to a headstage of an Axoclamp 2A amplifier (Axon Instruments). Data in voltage- and current-clamp modes were acquired via a Digidata 1322 (Molecular Devices) interface connected to a computer running with pCLAMP 8.2 software (Axon Instruments) and filtered at $3 \mathrm{kHz}$. Data were stored and analyzed using a computer equipped with Clampex 9.2 software (Molecular Devices).

\section{Electrophysiological protocols}

Cells were maintained at a potential of $-75 \mathrm{mV}$ throughout the experiment, unless indicated otherwise. All voltages reported were corrected for a $+15 \mathrm{mV}$ liquid junction potential (Melnick et al., 2007). Data were collected from neurons displaying action potentials that overshot $0 \mathrm{mV}$, a stable holding current $(<50 \mathrm{pA})$, and a stable access resistance $(10-20$ $\mathrm{M} \Omega$ ) for $10 \mathrm{~min}$ before any experimental manipulations.

Resting membrane potential. Continuous trace recordings were obtained in current clamp without the injection of any current. Where applicable, a representative $10 \mathrm{~s}$ segment of resting membrane potential (RMP) recordings in control, NPY, and washout, was selected with Clampfit 9.2 (Molecular Devices), and then the membrane potential (voltage) values were averaged using Axum 5.0 (Mathsoft) for each cell. The RMP was determined as the membrane potential in control before any drug application.

Input resistance. Voltage responses to a family of $500 \mathrm{~ms}$ hyperpolarizing current steps (10 pA increments; 4 s interstimulus interval) elicited from a membrane potential of $-75 \mathrm{mV}$ were determined. Whole-cell input resistance $\left(R_{\text {in }}\right)$ of each cell was determined from the voltage response to a $-60 \mathrm{pA}$ current step.

Membrane excitability. Membrane excitability was assessed by examining action potential discharges in response to $1.5 \mathrm{~s}$ current ramp depolarizations. Action potential discharge was triggered from a holding voltage of $-75 \mathrm{mV}$ by four consecutive depolarizing current ramps at a rate of 20,40,60, and 80 pA/s (Balasubramanyan et al., 2006; Lu et al., 2006). Action potential responses were compared at a ramp rate of 60 $\mathrm{pA} / \mathrm{s}$, which was sufficient to evoke robust firing in all VMN neurons studied before and after NPY application. The rheobase was determined as the minimum amount of current required to initiate action potential firing from a membrane potential of $-75 \mathrm{mV}$. Action potentials were generated in response to a series of $10 \mathrm{pA}$ incremental depolarizing current steps $(250 \mathrm{~ms})$ beginning from the membrane potential of $-75 \mathrm{mV}$. All depolarizing steps were preceded by a brief $200 \mathrm{~ms}$ hyperpolarizing current step of $-60 \mathrm{pA}$.

Current-voltage relationship. The current-voltage $(I-V)$ relationships of the VMN neurons were determined in voltage clamp using a family of $250 \mathrm{~ms}$ voltage steps at $-10 \mathrm{mV}$ increments from +20 to $-70 \mathrm{mV}$ from $V_{\mathrm{h}}=-75 \mathrm{mV}$; the cell was returned to $V_{\mathrm{h}}$ for $5 \mathrm{~s}$ between each voltage steps. The steady-state current was measured immediately before the offset of each voltage pulse. The net current change between two conditions was calculated by subtracting the current response in the control condition from the current response in the experimental condition for each voltage step. The experimental reversal potential $\left(V_{\text {rev }}\right)$ of a conductance was measured as the $x$-intercept value, which was determined for each neuron by calculating the slope conductance between -85 and $-105 \mathrm{mV}$ for NPY-mediated currents, between -65 and $-85 \mathrm{mV}$ for muscimol-mediated currents, and between -55 and $-75 \mathrm{mV}$ for glucose-mediated currents using GraphPad Prism, version 4.03 (GraphPad Software); these values were then averaged over several neurons as indicated. The theoretical $V_{\text {rev }}$ for an ion was calculated using the Nernst equation. Only those effects that reversed at least in part on washout were included in the data set.

Miniature postsynaptic currents. EPSCs appeared as downward deflections when they were monitored during a continuous recording at a holding potential of $-75 \mathrm{mV}$, which was close to the $E_{\mathrm{Cl}}$ to reduce the occurrence of inhibitory events. IPSCs were monitored by a continuous trace recording at a holding potential of $-55 \mathrm{mV}$, and only outward currents, which appeared as upward deflections, were analyzed. EPSCs and IPSCs were recorded in separate cells. Only those effects of drug application that reversed at least in part on washout were included in the data set. Cumulative probability plots were generated by pooled data of 200 events from each cell (total number of events $=200 \times$ number of cells) before NPY application, at the maximal effect of NPY, and 15 min after NPY washout.

\section{Drug applications}

Pipette and aCSF solutions were prepared with HPLC grade water (Thermo Fisher Scientific). Low glucose conditions were mimicked by the perfusion of carbogenated aCSF containing the following (in $\mathrm{mm}$ ): $124 \mathrm{NaCl}, 3 \mathrm{KCl}, 1.3 \mathrm{MgSO}_{4}, 1.4 \mathrm{NaH}_{2} \mathrm{PO}_{4}, 0.5$ glucose, 9.5 sucrose, 26 $\mathrm{NaHCO}_{3}, 2.5 \mathrm{CaCl}_{2}(300-302 \mathrm{mOsm} / \mathrm{L})$. The selective agonists for the $\mathrm{Y}_{1}$ receptor, $\mathrm{F}^{7} \mathrm{P}^{34} \mathrm{NPY}\left(\left[\mathrm{Phe}^{7}, \mathrm{Pro}^{34}\right] \mathrm{NPY}\right), \mathrm{Y}_{2}$ receptor, $\mathrm{Ahx}{ }^{5-24} \mathrm{NPY}$ ([6-aminohexanoic $\left.\left.{ }^{5-24}\right] \mathrm{NPY}\right)$, and $\mathrm{Y}_{5}$ receptor, AlaAibNPY $\left(\left[\mathrm{hPP}^{1-17}\right.\right.$, $\left.\left.\mathrm{Ala}^{31} \cdot \mathrm{Aib}^{32}\right] \mathrm{hNPY}\right)$, were generous gifts from Dr. Annette BeckSickinger (University of Leipzig, Leipzig, Germany). The antagonists BIBO $3304((R)-N$-[[4-(aminocarbonylaminomethyl)-phenyl] methyl]$N^{2}$-(diphenylacetyl)-argininamide trifluoroacetate) and BIIE 0246 $\left((S)-N^{2}-[[1-[2-[4-[(R, S)-5,11\right.$-dihydro-6(6h)-oxodibenz[b,e] azepin-11 -yl]-1-piperazinyl]-2-oxoethyl]cylopentyl] acetyl]- $N$-[2-[1,2-dihydro-3, 5(4H)-dioxo-1,2-diphenyl-3H-1,2,4-triazol-4-yl] ethyl]argininamid) were generous gifts from Dr. H. Doods (Boehringer-Ingelheim, Biberach, Germany), while the antagonist Novartis2 (trans-naphthalene-2-sulfonic acid (4-((4-(2-dimethylaminopropyl amino)quinazolin-2-ylamino)methyl) cyclohexylmethyl)amide) was a generous gift of Dr. P. Hipskind (Lilly Research Laboratories, Indianapolis IN). NPY was purchased from Peptidec Technologies; tetrodotoxin (TTX) was from Alomone Labs; glibenclamide, diazoxide, $R$-(+)-7-chloro-8-hydroxy-3-methyl-1-phenyl-2,3,5-tetrahydro-1 
H-3-benzazepine hydrochloride (SCH23390), and bicuculline were from Tocris; Neurobiotin was from Vector Laboratories; creatine and NaGTP were from Roche Diagnostics; and leptin was from National Hormone and Peptide Program (Torrance, CA). All other chemical agents used were purchased from Sigma-Aldrich. All drugs were diluted into aCSF from concentrated stock solutions (prepared in HPLC grade water and then stored at $-20^{\circ} \mathrm{C}$ ) to their final concentrations immediately before use and perfused into the recording chamber for a minimum of $3 \mathrm{~min}$. Stock solutions of leptin were prepared in potassium PBS (KPBS) containing the following (in $\mathrm{mM}$ ): $154 \mathrm{NaCl}, 16.4$ $\mathrm{K}_{2} \mathrm{HPO}_{4}, 3.6 \mathrm{KH}_{2} \mathrm{PO}_{4}, \mathrm{pH} 7.8$, and then diluted to the working concentration with aCSF immediately before use. After each drug application, the slice was continuously washed with aCSF for a minimum of 20 min before any additional next drug application.

\section{Immunohistochemistry}

Immunohistochemistry procedures were adapted from previously established protocols (Cowley et al., 2003; Melnick et al., 2007). After patch-clamp recordings, brain slices from LepRb ${ }^{\text {EGFP }}$ transgenic animals were fixed overnight in a $4 \%$ paraformaldehyde-sodium PBS, $\mathrm{pH}$ 7.4, fixative at $4^{\circ} \mathrm{C}$ and washed three times for $10 \mathrm{~min}$ in KPBS; then they were dehydrated at $4^{\circ} \mathrm{C}$ in $25 \%$ sucrose for 2 $\mathrm{d}$ and washed three times ( $10 \mathrm{~min}$ each) with KPBS. All antibody mixtures were diluted in $0.02 \mathrm{M}$ KPBS with $0.3 \%$ Triton X-100 (Sigma-Aldrich) and $2 \%$ normal goat serum (Rockland Immunochemicals). The slices were incubated for $48 \mathrm{~h}$ at $4^{\circ} \mathrm{C}$ in mouse anti-green fluorescent protein (GFP) (Millipore Bioscience Research Reagents; 1:500) (Cowley et al., 2003), and then washed five times for 10 min each with KPBS. Next, they were incubated for $1 \mathrm{~h}$ at room temperature $\left(23^{\circ} \mathrm{C}\right)$ in a mixture of secondary antibodies (all from Invitrogen) comprising anti-mouse Alexa 540 (1:300) and streptavidin-conjugated Oregon Green 488 (1:300), and then washed three times for 10 min each with KPBS before being mounted on glass microscope slides using Prolong antifading medium (Invitrogen). Images were taken and processed on a Zeiss LSM510 confocal microscope. All images were acquired with Zeiss LSM Image Browser software, version 4.2 .

\section{Data analysis}

Data were analyzed using Clampfit 9.2 (Molecular Devices). Sample traces were displayed and plotted using Axum 5.0 (Mathsoft). Miniature postsynaptic current events were analyzed using Clampfit 9.2 (Molecular Devices) or Mini Analysis Program, version 6 (Synaptosoft). Mean membrane current was calculated using Axum 5.0 software. Statistics and graphs were produced using GraphPad Prism, version 4.03 (GraphPad Software). Statistical significance for mean comparisons before and after a drug application involving only two groups was determined by the paired Student's $t$ test and that involving three or more groups was determined by the repeated-measures

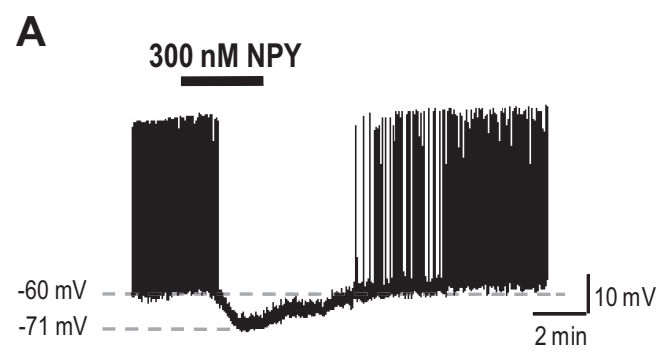

C
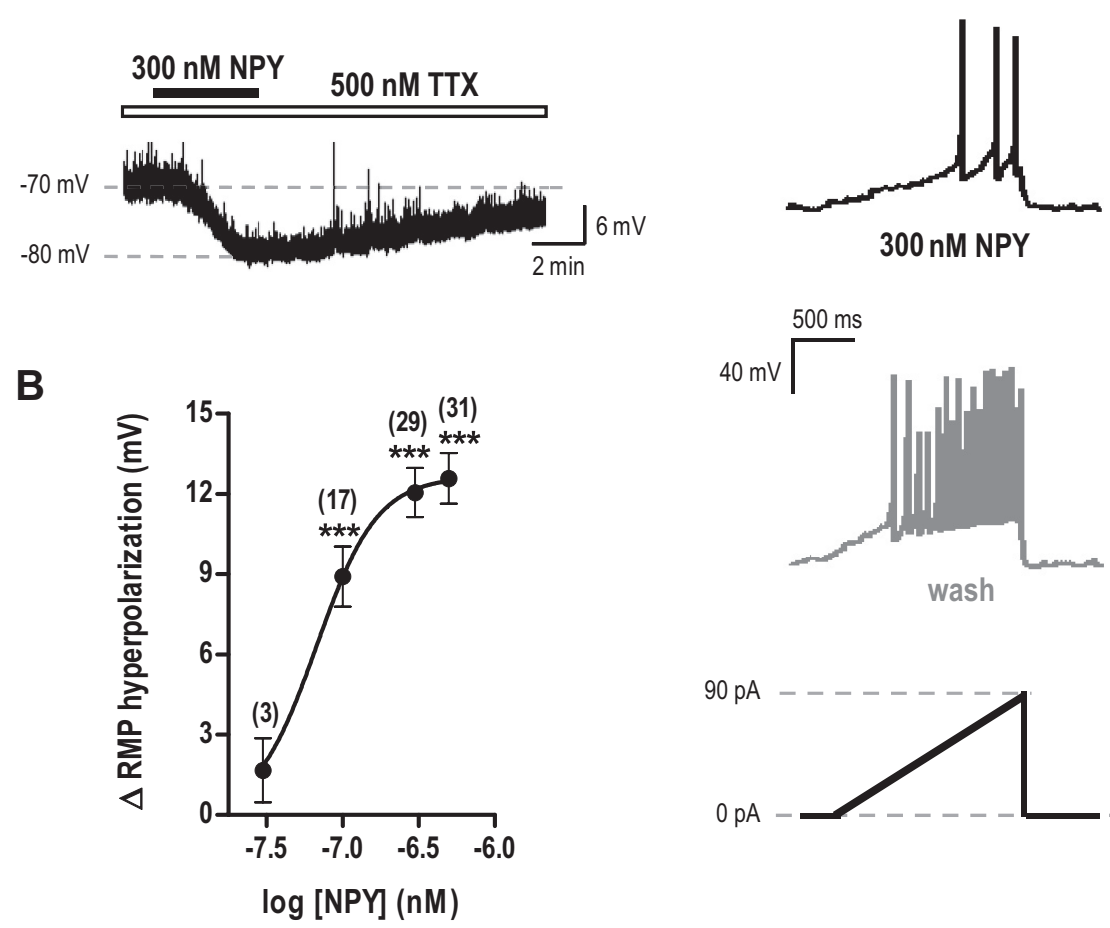

D
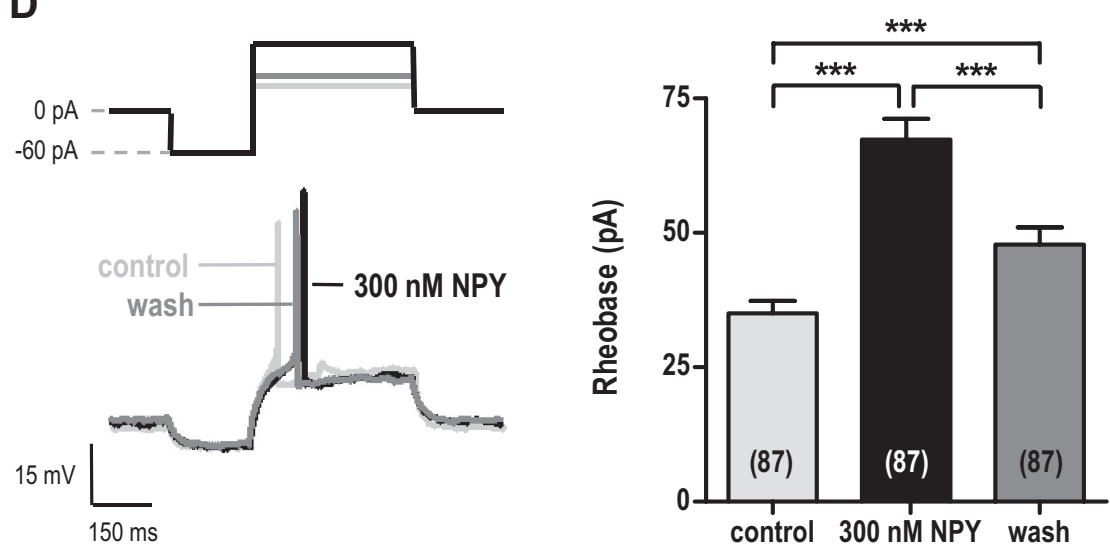

Figure 1. NPY inhibits VMN neurons postsynaptically. $\boldsymbol{A}$, Top, Sample trace of the change in RMP and the inhibition of spontaneous action potential firing of a VMN neuron by $300 \mathrm{~nm}$ NPY. Bottom, Sample trace of the change in RMP elicited by $300 \mathrm{~nm}$ NPY in the presence of $500 \mathrm{~nm}$ TTX to block action potential-dependent synaptic transmission. $\boldsymbol{B}$, Concentration-dependent change in RMP hyperpolarization with NPY application. C, Top, Action potential trains generated by a VMN neuron in control (light gray), 300 nм NPY (black), and washout (dark gray), in response to a depolarizing current ramp protocol (bottom) elicited from $-75 \mathrm{mV}$ at a ramp rate of $60 \mathrm{pA} / \mathrm{s}$. D, Top left, Superimposed action potential responses discharged at the rheobase of the VMN neuron in control (light gray), NPY (black), and washout (dark gray). Bottom left, Superimposed traces of a current step protocol used to trigger action potential firing in control (light gray), 300 nм NPY (black), and washout (dark gray). Depolarizing current steps were all preceded by a $125 \mathrm{~ms}, 60 \mathrm{pA}$ hyperpolarizing current step that was elicited from a membrane potential of $-75 \mathrm{mV}$. A larger current depolarization was required to trigger action potentials in the presence of NPY. No depolarizing current step was introduced when attempting to elicit low-threshold spikes (dashed light gray). Right, Mean rheobase of VMN neurons in control, NPY, and washout. All values are represented as the mean \pm SEM. ${ }^{* * *} p<0.0001$. 
Table 1. Effect of NPY on the basal properties of VMN neurons

\begin{tabular}{|c|c|c|c|c|}
\hline \multirow[b]{2}{*}{ Property } & \multicolumn{4}{|c|}{ Effect of 300 nm NPY on VMN neurons } \\
\hline & $n$ & Control $^{a}$ & 300 nм NPY $^{b}$ & $p$ value \\
\hline Resting membrane potentiall (mV) & 147 & $-68.9 \pm 0.6$ & $-79.6 \pm 0.6$ & $* * *$ \\
\hline Input resistance $(M \Omega)$ & 65 & $388.3 \pm 13.0$ & $247.2 \pm 11.4$ & $* * *$ \\
\hline Rheobase (pA) & 87 & $35.1 \pm 2.3$ & $67.4 \pm 3.9$ & *** \\
\hline Membrane current ${ }^{d}(\mathrm{pA})$ & 7 & $2.9 \pm 10.8$ & $39.3 \pm 11.0$ & $* *$ \\
\hline
\end{tabular}

All values are reported as the mean \pm SEM.

${ }^{a}$ Only the control values of NPY-sensitive VMN neurons were reported here.

${ }^{b}$ All effects of NPY were fully reversed upon washout.

'More than 250 NPY-sensitive VMN neurons have been identified throughout this study. This data set reflects the effect of NPY on untreated VMN neurons only.

${ }^{d}$ Steady-state membrane current was determined at a membrane potential of $-75 \mathrm{mV}$ in the presence of $500 \mathrm{~nm}$ tetrodotoxin.

All statistical comparisons were made by the repeated-measures one-way ANOVA with Bonferroni's multiplecomparison post test. ${ }^{* *} p<0.01 ;{ }^{* * *} p<0.001$.

one-way ANOVA with Bonferroni's multiple-comparison post test, unless otherwise indicated. Statistical significance between two means in an $I-V$ relationship was compared using a repeated-measures two-way ANOVA with a Bonferroni multiple-comparison post test. Statistical significance for single means was compared with 0 using a one-sample Student $t$ test. The concentration-response curve was fit with a nonlinear regression sigmoidal dose- response equation. The Kolmogorov-Smirnov two-sample statistical test was performed using Mini Analysis Program (Synaptosoft) and used to compare the distributions of amplitudes or interevent intervals in the cumulative probability plots. The mean differences were considered to be significant at $p<0.05$. Results were reported as mean \pm SEM where appropriate.

\section{Results}

\section{NPY directly hyperpolarizes VMN neurons}

Whole-cell recordings were obtained from $>250$ neurons in the dorsomedial (dm) and central (c) subdivisions of the VMN. At rest, $\sim 30 \%$ of VMN neurons (76 of 266) spontaneously fired action potentials. Bath application of $300 \mathrm{nM}$ NPY completely suppressed action potential firing in all spontaneously active VMN neurons (Fig. 1A). NPY also induced a reversible RMP hyperpolarization of up to $22.0 \mathrm{mV}$ (Table 1) that was concentration dependent above the threshold of $30 \mathrm{nM}\left(\mathrm{EC}_{50}=68 \mathrm{nM}\right)$ (Fig. $1 B$ ). Consistent with a direct, postsynaptic site for the actions of NPY, pretreatment with $500 \mathrm{~nm}$ TTX to block activitydependent synaptic transmission did not alter the NPY-mediated hyperpolarization (without TTX, $9.8 \pm 0.9 \mathrm{mV} ; n=8$; with TTX pretreatment, $7.9 \pm 1.1 ; n=8)($ Fig. $1 A$ ).

\section{NPY suppresses the excitability of VMN neurons}

Since membrane hyperpolarization can increase action potential firing threshold, we determined the effects of NPY on the excitability of VMN neurons by comparing action potential responses to steps and ramps of depolarizing current. Application of $300 \mathrm{nM}$ NPY significantly reduced the number of action potentials elicited after a 90 pA current ramp depolarization (by $57.6 \pm 3.6 \%$; $n=55 ; p<0.0001$ ) (Fig. $1 C$ ). Changes in VMN neuronal excitability were quantified by measuring the threshold current step required to elicit an action potential, also known as the rheobase. At the peak effect of $300 \mathrm{nM} \mathrm{NPY,} \mathrm{there} \mathrm{was} \mathrm{a} \mathrm{reversible} \mathrm{increase}$ in the rheobase by $114.2 \pm 9.9 \%(n=87 ; p<0.0001)$ (Table 1 , Fig. $1 D)$, verifying that the VMN neurons are less excitable in the presence of NPY.

\section{NPY activates a G-protein-coupled inwardly rectifying potassium current}

The application of $300 \mathrm{~nm}$ NPY also reversibly reduced the $R_{\text {in }}$ of VMN neurons (Table 1), consistent with the hyperpolarization resulting from an increase in the activity of a membrane ion channel. The ionic basis of the NPY-mediated hyperpolarization was determined in voltage clamp by comparing the $I-V$ relationship of NPY-sensitive VMN neurons before and after NPY application (Fig. 2A). NPY increased the membrane conductance and produced a net current with a $V_{\text {rev }}$ of $-92.0 \pm 3.1 \mathrm{mV}(n=8)$, close to the predicted potassium equilibrium potential $\left(E_{\mathrm{K}}\right)$ of $-95 \mathrm{mV}$ for our experimental conditions (Fig. $2 \mathrm{~B}$ ). Furthermore, with NPY application, the net increase in inward current at potentials negative to $E_{\mathrm{K}}$ was greater than the net outward current at potentials positive to $E_{\mathrm{K}}$ (Fig. $2 \mathrm{~B}$ ). Together, these results are consistent with the activation of an inwardly rectifying potassium channel (IRK).

The two main populations of IRKs in the VMN are the G-protein-coupled IRK (GIRK) (Perry et al., 2008) and the ATPsensitive potassium channel $\left(\mathrm{K}_{\mathrm{ATP}}\right)$ (Karschin et al., 1996; Kang et al., 2004). Extracellular barium $\left(\mathrm{Ba}^{2+}\right)$ is commonly used to block the activation of GIRKs (Williams et al., 1988; Slesinger, 2001 ), but this is complicated by the sensitivity of $\mathrm{K}_{\mathrm{ATP}}$ channels to $\mathrm{Ba}^{2+}$ at concentrations $\geq 100 \mu \mathrm{M}$ (Takano and Ashcroft, 1996). We thus determined the effect of increasing $\mathrm{Ba}^{2+}$ concentrations $(10,30$, and $100 \mu \mathrm{M})$ on the actions of NPY in VMN neurons. Although $100 \mu \mathrm{M} \mathrm{Ba}^{2+}$ completely blocked the NPYmediated hyperpolarization (by $115.9 \pm 10.0 \% ; n=6$ ), it was only partially reduced by $10 \mu \mathrm{M} \mathrm{Ba}^{2+}(51.3 \pm 18.0 \% ; n=10)$. However, $30 \mu \mathrm{M} \mathrm{Ba}^{2+}$ almost entirely blocked the effects of NPY on the RMP (by $85.0 \pm 7.8 \% ; n=11$ ) and membrane conductance (Fig. 2C), thus suggesting that the effects of NPY are not mediated by $\mathrm{K}_{\mathrm{ATP}}$ channels. In NPY-sensitive VMN neurons, application of $300 \mathrm{nM}$ glibenclamide to close $\mathrm{K}_{\mathrm{ATP}}$ channels depolarized these neurons ( $300 \mathrm{~nm} \mathrm{NPY,}-8.8 \pm 2.5 \mathrm{mV} ; 300 \mathrm{~nm}$ glibenclamide, $14.5 \pm 3.3 \mathrm{mV} ; n=4$ ), but when present, glibenclamide did not block the hyperpolarizing effects of NPY application (NPY in $300 \mathrm{~nm}$ glibenclamide, $-17.3 \pm 4.6 \mathrm{mV} ; n=4$ ). In the converse experiment, pretreatment with $500 \mu \mathrm{M}$ diazoxide to open $\mathrm{K}_{\mathrm{ATP}}$ channels did not occlude the effects of NPY (300 nM $\mathrm{NPY},-16.7 \pm 1.5 \mathrm{mV} ; 500 \mu \mathrm{M}$ diazoxide, $-2.9 \pm 0.9 \mathrm{mV}$; NPY in $500 \mu \mathrm{M}$ diazoxide, $-11.3 \pm 3.3 \mathrm{mV} ; n=5$ ). These results indicated that NPY responses in VMN neurons were not mediated by $\mathrm{K}_{\mathrm{ATP}}$ channel activation.

We then determined the effect of NPY in the presence of a GIRK blocker, SCH23390 (Kuzhikandathil and Oxford, 2002). Pretreatment of an NPY-sensitive neuron with $15 \mu \mathrm{M} \mathrm{SCH} 23390$ completely blocked the NPY-mediated change in RMP and conductance (Fig. 2D). To determine whether GIRK activation accounts entirely for NPY actions, the net current induced by NPY was compared with that induced by the $\mathrm{GABA}_{\mathrm{B}}$ receptor agonist, baclofen. Baclofen $(10 \mu \mathrm{M})$, which strongly activates a GIRK conductance in most neurons (Sodickson and Bean, 1996), elicited a larger conductance change in VMN neurons than did NPY, but the normalized net current induced both by baclofen and NPY was comparable over the entire $I-V$ relationship. In the presence of baclofen, NPY did not further increase membrane current (Fig. 2E), which is consistent with both NPY and baclofen activating the same population of GIRK channels.

\section{NPY in the VMN acts via the $Y_{1}$ receptor}

The $Y_{1}, Y_{2}$, and $Y_{5}$ receptors have all been implicated in the hypothalamic regulation of energy balance (Pronchuk et al., 2002; Beck, 2006); thus, we determined the contributions of each to the actions of NPY on VMN neurons. $Y_{1}$ (Kopp et al., 2002; Kishi et al., 2005; Eva et al., 2006) but not $Y_{2}$ (Stanić et al., 2006) or $Y_{5}$ (Morin and Gehlert, 2006) receptor expression has been demon- 
strated in the VMN. Consistent with this, the selective $\mathrm{Y}_{1}$ receptor agonist $\mathrm{F}^{7} \mathrm{P}^{34} \mathrm{NPY}(300 \mathrm{~nm})$ elicited a robust, reversible RMP hyperpolarization $(-12.0 \pm$ $3.0 \mathrm{mV} ; n=6 ; p<0.01$ ) (Fig. $3 A$ ) that was similar to that caused by $300 \mathrm{nM}$ NPY in the same neuron (Fig. 3B). However, neither selective agonists for the $\mathrm{Y}_{2}(1 \mu \mathrm{M}$ $\left.\mathrm{Ahx}^{5-24} \mathrm{NPY}\right)$ nor $\mathrm{Y}_{5}$ receptors (1 $\mu \mathrm{M}$ AlaAibNPY) (Pronchuk et al., 2002) affected the RMP of NPY-sensitive VMN neurons (Fig. 3B).

To confirm the results from the agonist experiments, we next tested the effects of receptor-selective antagonists to block the effects of NPY itself (El Bahh et al., 2005). The $Y_{1}$ receptor antagonist BIBO 3304 (300 nM) completely blocked the NPY-mediated hyperpolarization (Fig. $3 A, B)$ and conductance change (Fig. 3C). However, neither the $\mathrm{Y}_{2}$ (300 nM BIIE 0246) nor $\mathrm{Y}_{5}$ receptor antagonist (300 nM Novartis2) affected the actions of NPY (Fig. 3B). Interestingly, none of these antagonists alone had any significant effect on the RMP, suggesting that there is little or no tonic NPY signaling in the VMN slice (El Bahh et al., 2005; Tu et al., 2005). These results indicated that postsynaptic NPY responses in VMN neurons were mediated solely by $\mathrm{Y}_{1}$ receptors and are consistent with the $Y_{1}$ receptor-mediated orexigenic effects.

Convergence of glucose signals onto NPY-sensitive VMN neurons

A subpopulation of VMN neurons are sensitive to changes in extracellular glucose concentrations, which either excite (GE) or inhibit (GI) these neurons (Routh, 2003). However, it remains unclear whether glucose and energy balance-related signals converge on VMN neurons. Therefore, we determined whether NPY-sensitive VMN neurons are also sensitive to changes in extracellular glucose concentrations.

Approximately 75\% of NPY-sensitive neurons (23 of 29) in the dm- and c-VMN were also glucosensitive. Decreasing extracellular glucose from 2.5 to $0.5 \mathrm{~mm}$ produced a gradual RMP depolarization of $+6.8 \pm 0.8 \mathrm{mV}(n=23 ; p<0.0001)$ (Fig. $4 A$ ). These glucose-mediated effects persisted in $500 \mathrm{nM}$ TTX, thus supporting our hypothesis that both glucose and NPY signals directly converge onto the same VMN neuron. Interestingly, decreasing extracellular glucose did not hyperpolarize any NPY-sensitive VMN neurons tested, thus indicating that these are all GI neurons. NPY hyperpolarized VMN neurons in 2.5 or $0.5 \mathrm{~mm}$ glucose to a similar extent (Fig. $4 \mathrm{~B}$ ). Since the actions of NPY were unaffected by the change in glucose concentration, this suggested that NPY and glucose signaling occur independently of one another, via different ionic mechanisms in these VMN neurons.

B
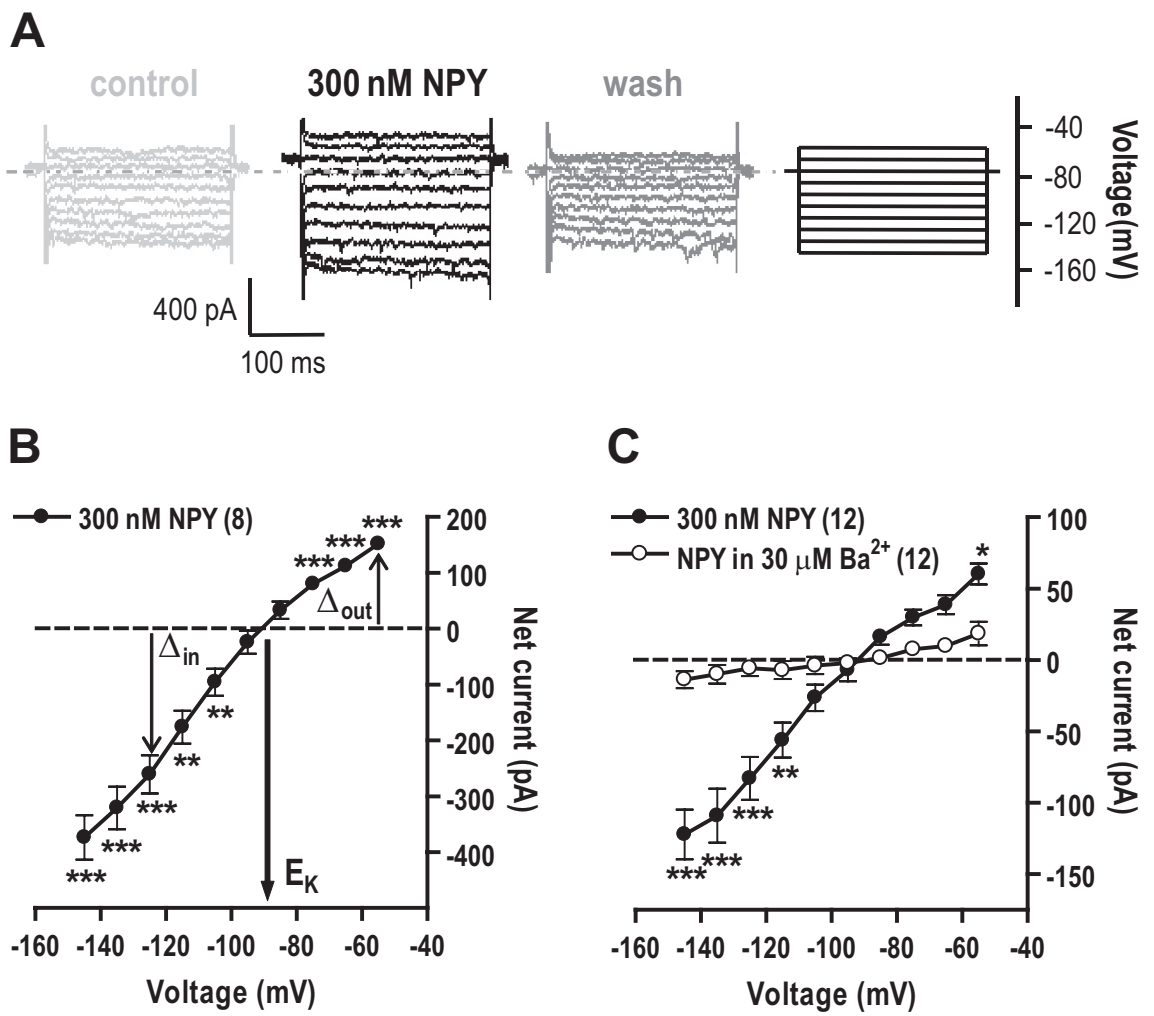

C
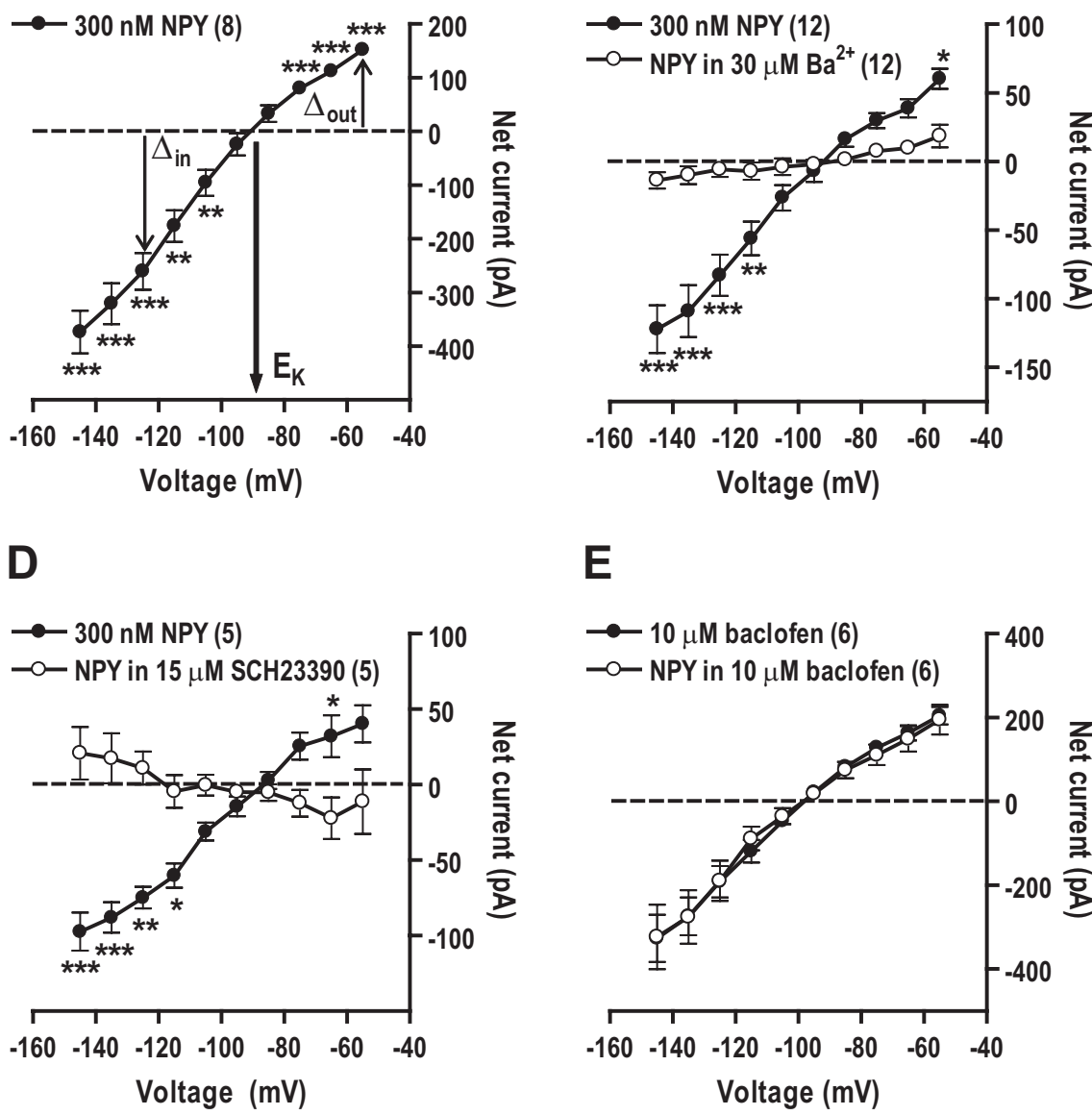

E

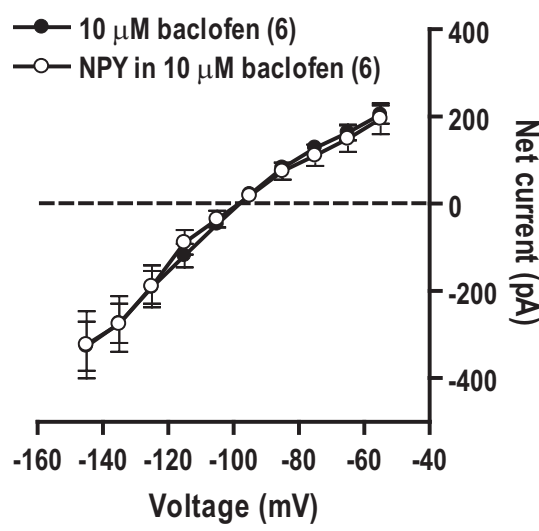

Figure 2. NPY activates a GIRK in VMN neurons. $\boldsymbol{A}$, Left, Sample trace of membrane currents elicited in response to a family of voltage steps (right) in control, $300 \mathrm{~nm} \mathrm{NPY,} \mathrm{and} \mathrm{washout.} \mathrm{Larger} \mathrm{responses} \mathrm{after} \mathrm{NPY} \mathrm{application} \mathrm{indicated} \mathrm{an} \mathrm{increase} \mathrm{in} \mathrm{mem-}$ brane conductance. Right, Voltage steps elicited from a holding potential of $-75 \mathrm{mV}$ in $-10 \mathrm{mV}$ increments from -55 to -145 $\mathrm{mV}$. $\boldsymbol{B}$, Current-voltage $(I-V)$ relationship for the mean net current induced by NPY. Inward rectification was demonstrated by comparison of the net inward $\left(\Delta_{\text {in }}\right)$ to net outward current increase $\left(\Delta_{\text {out }}\right)$. C, Mean net current induced in VMN neurons by NPY (O) was almost entirely blocked in the presence of $30 \mu \mathrm{m} \mathrm{Ba}{ }^{2+}(O)$. D, Mean net current induced in VMN neurons by NPY $(O)$ was completely blocked in the presence of the GIRK blocker, $15 \mu \mathrm{mSCH} 23390$ (О). $\boldsymbol{E}$, Mean net current induced in VMN neurons by NPY (O) in the absence and presence of $10 \mu \mathrm{m}$ baclofen (O). Actions of NPY were occluded in the presence of baclofen. All values are represented as the mean \pm SEM. ${ }^{*} p<0.05 ;{ }^{* *} p<0.01 ;{ }^{* * *} p<0.001$.

Decreasing the extracellular glucose concentration also increased the membrane conductance of VMN neurons. In contrast to the $V_{\text {rev }}$ of the NPY-induced current, the current induced by lowering extracellular glucose reversed at $-67.9 \pm 3.8 \mathrm{mV}$ $(n=4)$ (Fig. 4C). Meanwhile, the current induced by NPY in 0.5 mu glucose $(-94.2 \pm 8.9 \mathrm{mV} ; n=4)$ reversed near $E_{\mathrm{K}}$ for our conditions (Fig. 4C). The GI current was also significantly positive to the current induced by the $\mathrm{GABA}_{\mathrm{A}}$ agonist, muscimol $\left(V_{\text {rev }}=-80.4 \pm 1.4 \mathrm{mV} ; n=6 ; p<0.01\right)$, a predominantly 


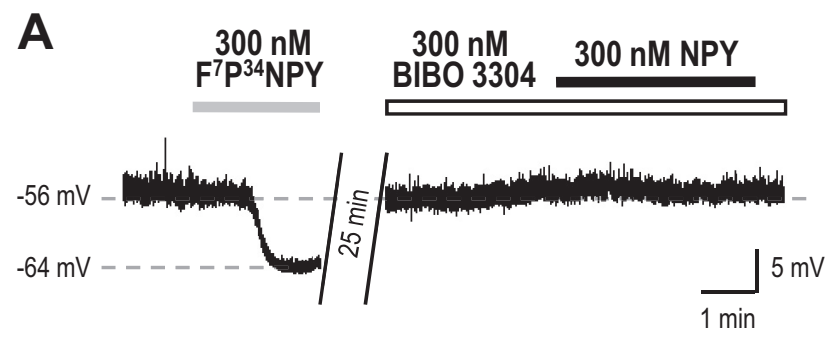

B

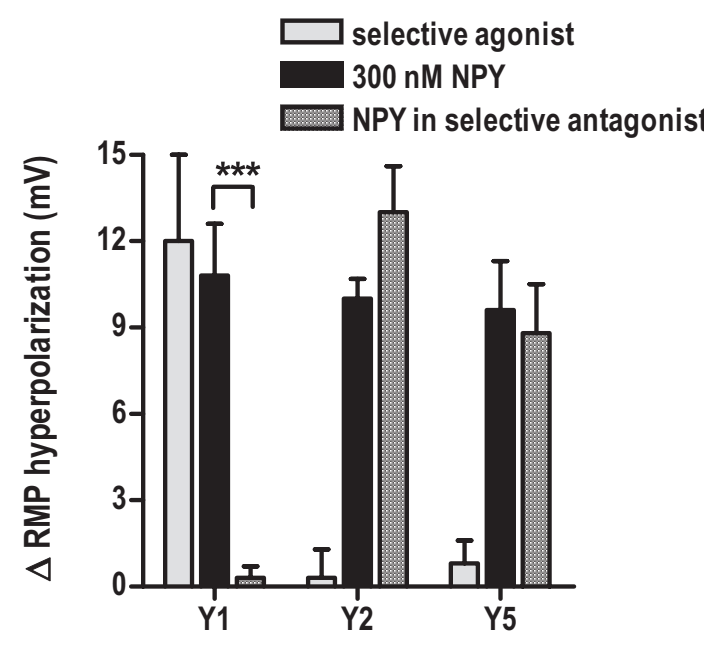

C

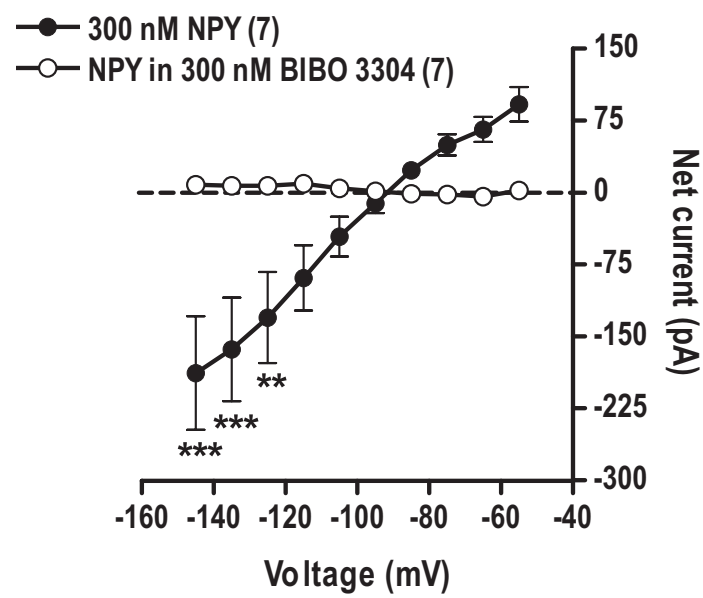

Figure 3. NPY activates only the $Y_{1}$ receptor subtype in the VMN. $\boldsymbol{A}$, Sample trace of the membrane hyperpolarization induced in a VMN neuron by $300 \mathrm{~nm} \mathrm{~F}^{7} \mathrm{P}^{34} \mathrm{NPY}$, the selective $Y_{1}$ receptor agonist. After 25 min washout of $\mathrm{F}^{7} \mathrm{P}^{34} \mathrm{NPY}$, pretreatment with the $\mathrm{Y}_{1}$ receptor antagonist BIBO 3304 completely blocked the response of the same neuron to $300 \mathrm{~nm} \mathrm{NPY.} \mathrm{B,} \mathrm{Mean}$ RMP hyperpolarization of VMN neurons by selective agonists for $Y_{1}\left(300 \mathrm{nM} \mathrm{F}^{7} \mathrm{P}^{34} \mathrm{NPY} ; n=6\right)$, $\mathrm{Y}_{2}\left(1 \mu \mathrm{M}\left[\mathrm{ahx} \mathrm{x}^{5-24}\right] \mathrm{NPY} ; n=4\right)$, and $\mathrm{Y}_{5}(1 \mu \mathrm{M}$ AlaAibNPY; $n=4)$ receptors; and the effect of 300 nм NPY in the absence or presence of antagonists selective for $Y_{1}(300 \mathrm{~nm} \mathrm{BIB0} 3304 ; n=10), Y_{2}$ ( 300 nм BIIE 0246; $n=6)$, and $Y_{5}(300$ nм Novartis $2 ; n=5)$ receptors. C, Mean net current generated by $300 \mathrm{~nm} \mathrm{NPY} \mathrm{(O)} \mathrm{in} \mathrm{the} \mathrm{absence} \mathrm{and} \mathrm{presence} \mathrm{of} 300 \mathrm{~nm} \mathrm{BIBO} 3304$, the selective $Y_{1}$ receptor antagonist $(\bigcirc)$. All values are represented as the mean \pm SEM. ${ }^{* *} p<0.01 ;{ }^{* * *} p<0.001$.

chloride-mediated conductance. Thus, the GI response is not necessarily mediated by a change in the chloride conductance but may result from the activation of multiple contributing ionic conductances, including one to chloride. These results indicated that, although glucose and NPY signals converge in the VMN, they are each mediated by independent and different ionic mechanisms.

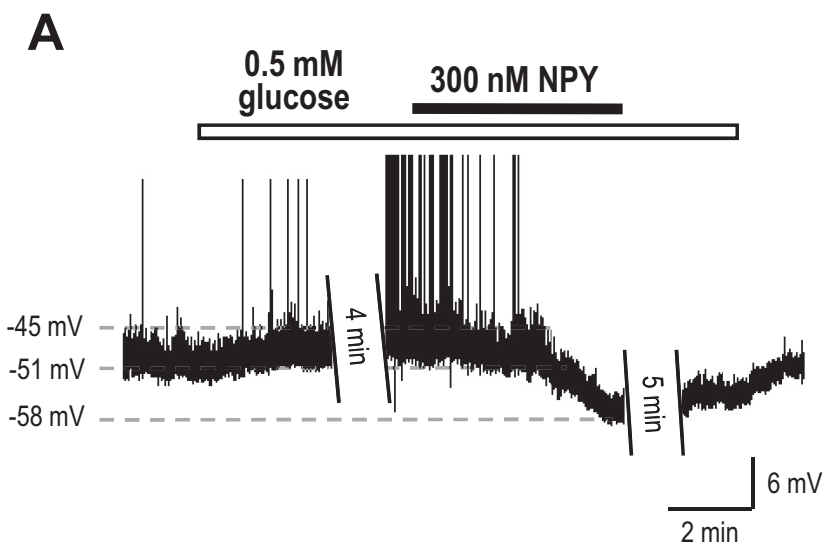

B

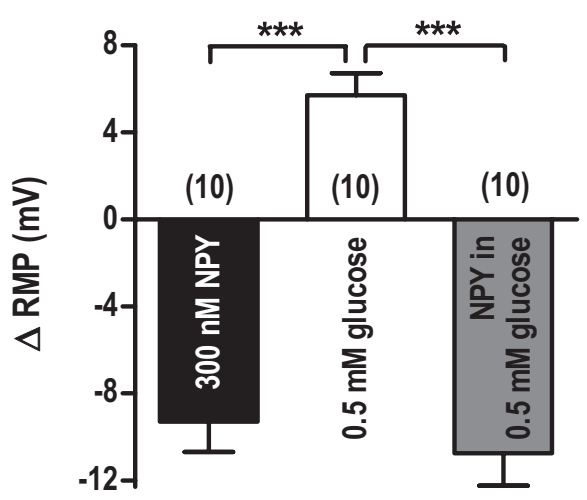

C

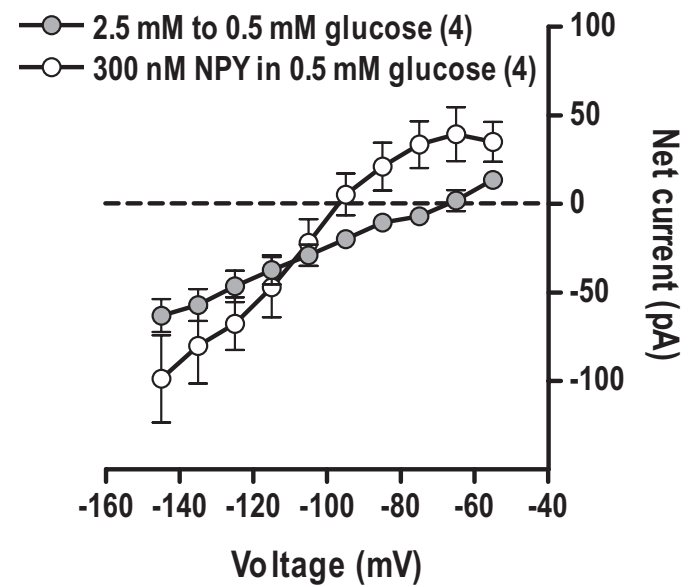

Figure 4. NPY-sensitive VMN neurons are inhibited by glucose. $A$, Sample trace of membrane depolarization induced in a VMN neuron by decreasing extracellular glucose from 2.5 to $0.5 \mathrm{~mm}$ and the actions of $300 \mathrm{~nm} \mathrm{NPY} \mathrm{on} \mathrm{the} \mathrm{same} \mathrm{neuron} \mathrm{that} \mathrm{was} \mathrm{unaltered} \mathrm{in} 0.5 \mathrm{~mm}$ glucose. $B$, Mean change in membrane potential by NPY was similar in either 2.5 or $0.5 \mathrm{~mm}$ glucose. A reduction in extracellular glucose depolarized the membrane potential. $C$, Mean net current induced in VMN neurons by decreasing extracellular glucose $(\mathbf{O})$ and by NPY in $0.5 \mathrm{~mm}$ glucose $(\bigcirc)$. Note the different reversal potentials for each current. All values are represented as the mean \pm SEM. ${ }^{* * *} p<0.001$.

Convergence of NPY and glucose signals in LepRb-expressing VMN neurons

Leptin signaling, via the long form of the leptin receptor LepRb, is required in the VMN for normal energy homeostasis and body weight regulation (Dhillon et al., 2006). Since NPY actions in the 
VMN are strongly orexigenic, we hypothesized that the LepRb-expressing VMN neurons presumably involved in energy homeostasis will also respond to NPY. We thus examined the NPY response of VMN cells from mice expressing EGFP specifically in LepRb-expressing cells (LepRb ${ }^{\text {EGFP }}$ mice) (Leshan et al., 2009). In these experiments, only VMN neurons expressing green fluorescence were studied (Fig. 5A,B).

Although the application of $100 \mathrm{~nm}$ leptinreversiblydepolarizedLepRb-expressing VMN neurons $(9.8 \pm 3.0 \mathrm{mV} ; n=5$; $p<0.05$ ) (Fig. 5C), nearly $80 \%$ of LepRbexpressing VMN neurons (47 of 59) were inhibited by NPY. NPY (300 nM) hyperpolarized LepRb-expressing VMN neurons $(-11.5 \pm 1.3 \mathrm{mV} ; n=31 ; p<0.0001)$ in a TTX-insensitive manner and increased the rheobase of LepRb-expressing VMN neurons, similar to responses observed in VMN neurons from wild-type mice (Fig. 5D). These effects were mediated by comparable changes in a GIRK conductance (data not shown).

When tested for their sensitivity to glucose, only $\sim 36 \%$ (4 of 11 ) of NPYsensitive LepRb-expressing VMN neurons responded. As with unidentified VMN neurons, responses were characteristic of GI neurons. Although this suggested a link between energy and glucose homeostasis at the LepRb-expressing VMN neurons, the relatively lower frequency of glucosensitivity in LepRb-expressing VMN neurons suggested that the two functions overlap in only a subset of neurons with an energy balancerelated role.

\section{NPY also depresses synaptic activity in VMN neurons}

The actions of NPY in the hypothalamus are frequently mediated by presynaptic mechanisms (Pronchuk et al., 2002; Acuna-Goycolea et al., 2005). We tested whether NPY also modulates synaptic transmission onto NPY-sensitive VMN neurons. In the presence of $500 \mathrm{nM}$ TTX, miniature EPSCs (mEPSCs) and miniature IPSCs (mIPSCs) were monitored during a continuous voltage-clamp recording while held at -75 and $-55 \mathrm{mV}$, respectively. NPY induced a reversible outward current at both holding potentials (Table 1). In these neurons, the mean baseline frequency of mEPSCs was $\sim 9 \mathrm{~Hz}$ and that of mIPSCs was $\sim 2.25 \mathrm{~Hz}$. NPY reduced the frequencies of miniature synaptic currents recorded in VMN neurons. Application of $300 \mathrm{~nm}$ NPY produced a rightward shift in the distribution of $\operatorname{mEPSC}(p<0.001)$ (Fig. $6 B)$ and mIPSC
A
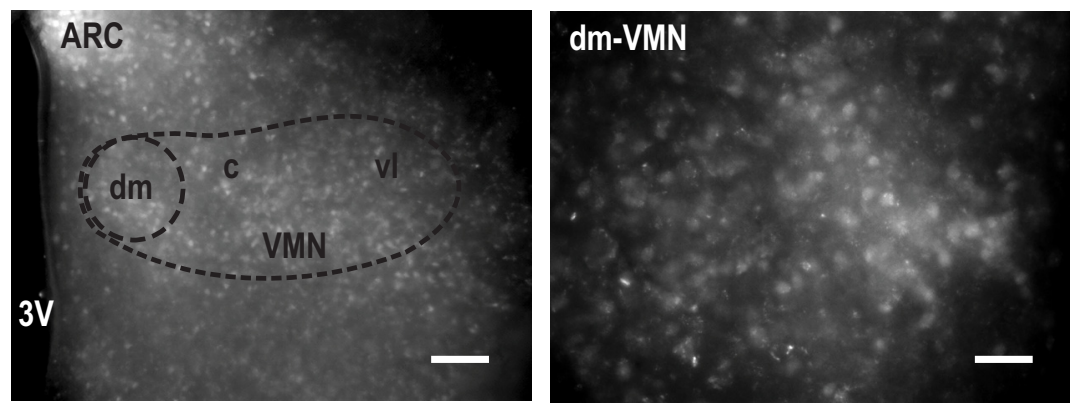

B
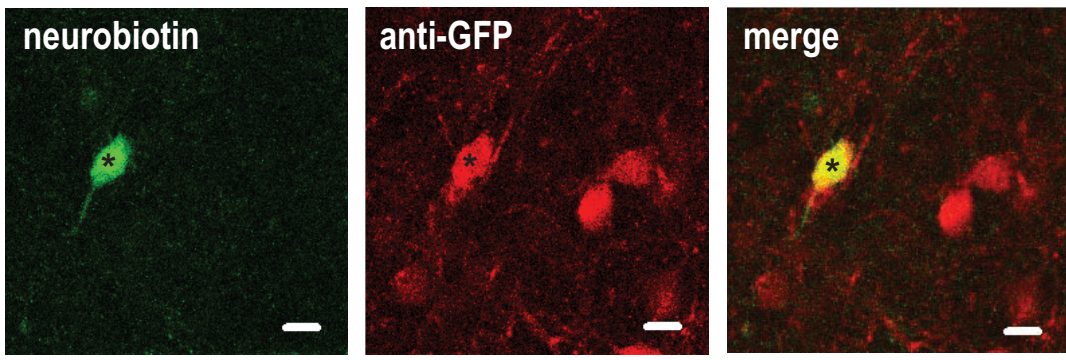

C

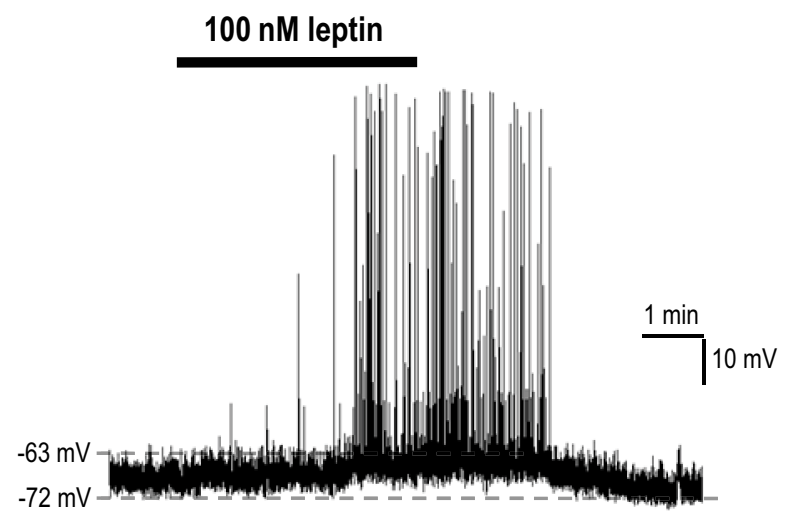

D

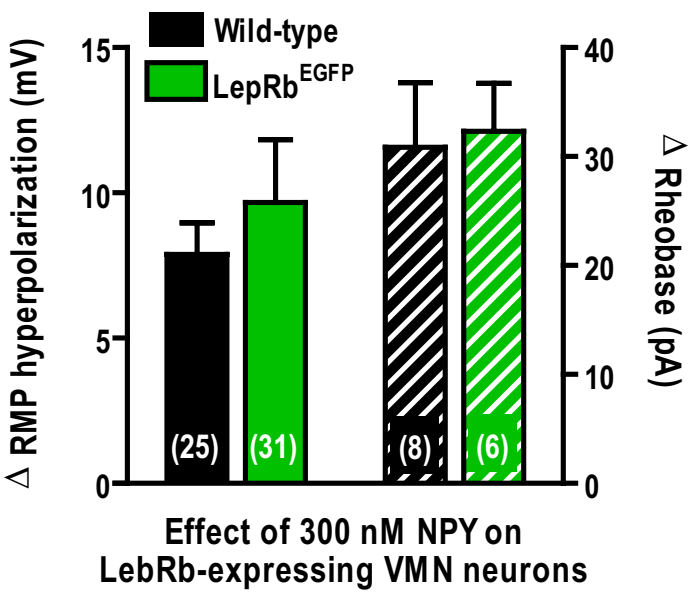

Figure 5. LepRb-expressing VMN neurons are inhibited by NPY. $\boldsymbol{A}$, Left, Representative epifluorescence image of an acute coronal brain slice containing fluorescent LepRb-expressing neurons in the VMN. The relative position of the VMN (outer dashed line) to the ARC and third ventricle (3V) is indicated. Scale bar, $100 \mu \mathrm{m}$. Right, The dm subdivision of the VMN (inner dashed circle; left panel) shown at higher magnification. Scale bar, $50 \mu \mathrm{m}$. B. Confocal image of a Neurobiotin-filled VMN neuron, denoted by an asterisk $(*)$, from a LepRb ${ }^{\text {EGFP }}$ mouse coimmunostained with a streptavidin-conjugated Oregon Green to identify the cell labeled intracellularly with pipette contents (green image; left) and with an antibody to GFP (red image; middle). Merged image of the Neurobiotin- and anti-GFP-labeled neuron confirm that recordings were made from a GFP-expressing neuron (right). All scale bars, $10 \mu \mathrm{m}$. C, Sample trace of the change in membrane depolarization induced by the application of $100 \mathrm{~nm}$ leptin. $\boldsymbol{D}$, Mean ( \pm SEM) effects of $300 \mathrm{~nm} \mathrm{NPY} \mathrm{on} \mathrm{the} \mathrm{RMP} \mathrm{(solid} \mathrm{bars)} \mathrm{and} \mathrm{rheobase} \mathrm{(hatched} \mathrm{bars)} \mathrm{were} \mathrm{indistinguishable} \mathrm{in} \mathrm{VMN} \mathrm{neurons} \mathrm{from} \mathrm{wild-type}$ (black bars) and LepRb ${ }^{\text {EGFP }}$ mice (green bars). 
A
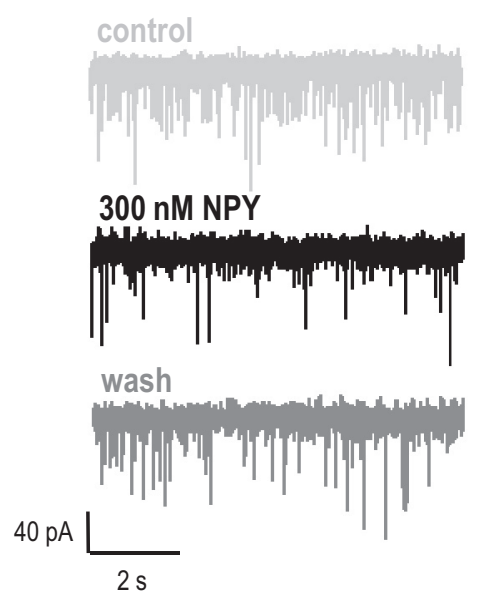

B

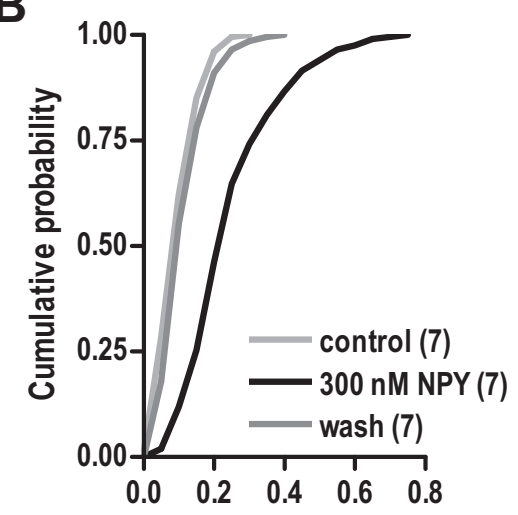

inter-mEPSC interval (s)

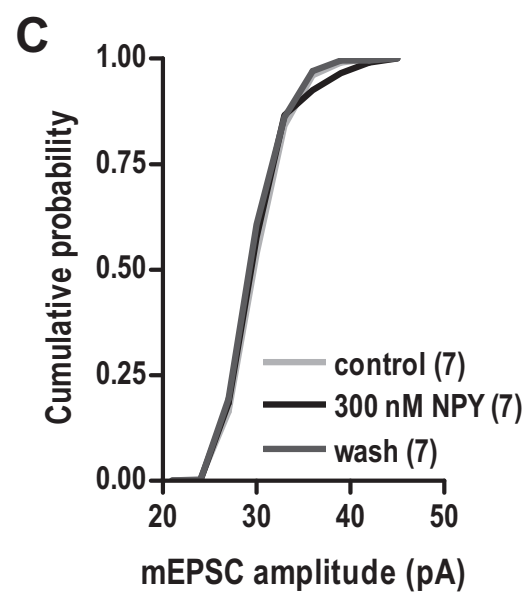

D

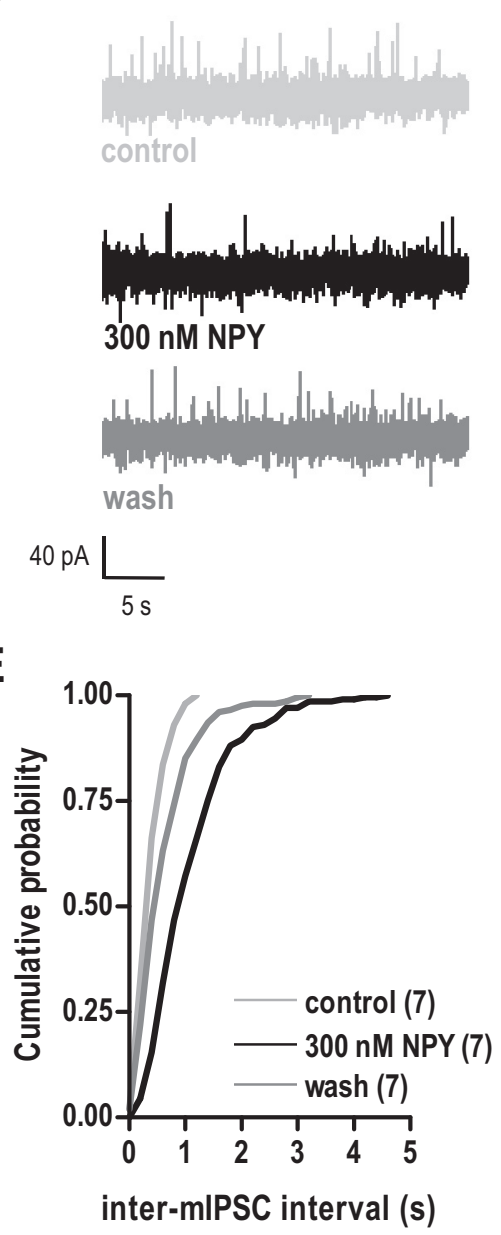

$\mathbf{F}$

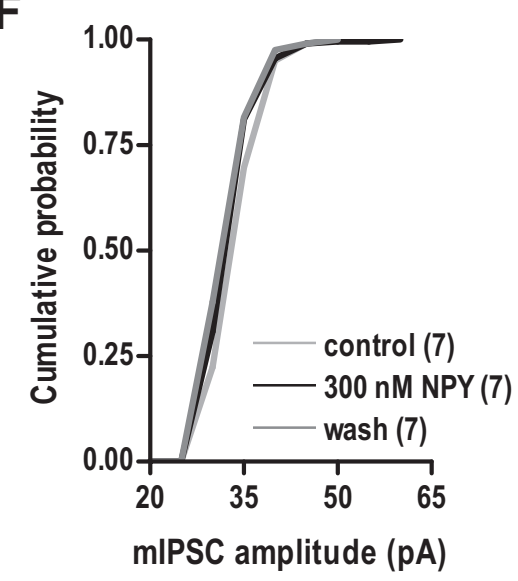

Figure 6. NPY also inhibits afferent inputs to NPY-sensitive VMN neurons. $\boldsymbol{A}$, Sample trace of mEPSCs (downward deflections) recorded in VMN neurons in $500 \mathrm{nM}$ TTX. NPY at $300 \mathrm{~nm}$ reversibly reduced the frequency of $\mathrm{mEPSC}$. $\boldsymbol{B}$, NPY right-shifted the cumulative probability plot for mEPSC intervals. C, NPY had no effect on mEPSC amplitudes. D, Sample trace of mIPSCS (upward deflections) recorded in VMN neurons in $500 \mathrm{~nm}$ TTX. NPY at $300 \mathrm{~nm}$ reversibly reduced the frequency of mEPSCs. $\boldsymbol{E}$, NPY rightshifted the cumulative probability plot for mIPSC intervals. $\boldsymbol{F}$, NPY had no effect on mIPSC amplitudes.

$(p<0.001)$ (Fig. 6E) interevent intervals. However, neither the amplitude distribution of mEPSCs (Fig. 6C) nor of mIPSCs (Fig. 6 F) was altered by NPY. These results indicated that NPY also presynaptically reduced transmitter release onto VMN neurons.

\section{Discussion}

NPY directly hyperpolarizes neurons of the $\mathrm{dm}$ - and c-VMN by activating a classical GIRK conductance; this response not only directly inhibited them but also reduced their sensitivity to depolarizing current inputs. This NPY response was seen in the great majority of LepRbexpressing, and some glucosensitive, VMN neurons. Furthermore, NPY also suppressed both excitatory and inhibitory synaptic inputs to NPY-sensitive VMN cells. NPY can directly influence the output of VMN neurons by a combination of dominantly postsynaptic actions, and complementary, but lesser, presynaptic actions. If excitatory output from the VMN actively suppresses food intake, as suggested both by lesion studies that included the VMN (Hetherington and Ranson, 1940) and more anatomically defined SF-1 KO studies (Majdic et al., 2002), then the postsynaptic (and presynaptic) inhibitory actions of NPY would promote orexigenic activity by synergistically suppressing output from LepRb-expressing neurons in the c-and dm-VMN.

NPY activates postsynaptic $Y_{1}$ receptors in the VMN

Although the actions of NPY in the VMN are mediated by both postsynaptic and presynaptic mechanisms, the postsynaptic actions dominate. There is a high density of agouti-related peptide (AgRP)/ NPY-immunoreactive axons in the VMN shell (Broberger et al., 1998; HaskellLuevano et al., 1999); VMN neurons can have long dendrites that extend out into the VMN shell to form synaptic contacts with NPY nerve terminals (Fu and van den Pol, 2008). However, the VMN core is not devoid of NPY projections (Broberger et al., 1998; Fetissov et al., 2003) and NPY released in the shell would also be expected to diffuse into the core to affect neuronal activity. The postsynaptic site of NPY action within the VMN core is consistent with the strong expression there of $\mathrm{Y}_{1}$ receptors (Kishi et al., 2005; Eva et al., 2006) and is also consistent with a previous report showing the $\mathrm{Y}_{1}$-mediated inhibition of VMN neurons (Kumarnsit et al., 2003). In addition, these experiments show the postsynaptic NPY response to be entirely $\mathrm{Y}_{1}$-mediated and provide insight into the abundance of NPY-sensitive neurons in the VMN. Neither the $Y_{2}$ (Stanić et al., 2006) nor $Y_{5}$ receptors (Morin and Gehlert, 2006) are expressed in the VMN, nor did we observe any postsynaptic effects that were not mediated entirely by $\mathrm{Y}_{1}$ receptors. Together with the reported suppression of food intake after the application of antisense 
oligodeoxynucleotides to $\mathrm{Y}_{1}$ receptors in the VMN (LopezValpuesta et al., 1996), the present results underscore the importance of $Y_{1}$ receptors to the VMN NPY response.

NPY has potent orexigenic actions within the VMN that likely result mostly from the postsynaptic inhibitory actions described here. In other hypothalamic regions, notably the paraventricular nucleus, however, NPY appears to act predominantly at presynaptic sites to regulate energy balance (Chee and Colmers, 2008). In addition to the potent postsynaptic actions, we also observed that NPY consistently reduced the frequency both of excitatory and inhibitory synaptic events in the VMN. Although an action to suppress GABAergic input appears counterintuitive in this model, the basal frequency of GABAergic synaptic events in the VMN was approximately fourfold lower than that for glutamate. Thus, the effect of NPY on excitatory glutamatergic transmission would be expected to predominate; this is consistent with observations by others (Fu and van den Pol, 2008). Glutamatergic inputs to VMN neurons can arise from intra-VMN collateral connections (Canteras et al., 1994); hence any postsynaptic inhibitory actions of NPY on VMN neurons would be abetted by the suppression of collateral excitation. In effect, NPY could suppress a regenerative excitatory tone within the VMN, whose output is anorexigenic. These combined actions of NPY would interact synergistically at several physiological targets within the VMN to reduce its output and thus unleash orexigenic behaviors.

\section{NPY activates a GIRK in VMN neurons}

We determined that GIRKs and $\mathrm{K}_{\mathrm{ATP}}$ channels were both expressed by NPY-sensitive VMN neurons, but several lines of evidence converged to demonstrate that the actions of NPY in the VMN were solely mediated by the activation of GIRKs. NPY has also been shown to exert inhibitory effects by activating GIRK channels in other hypothalamic neuronal populations (Fu et al., 2004; Roseberry et al., 2004; Acuna-Goycolea et al., 2005). The net current induced by NPY rectified inwardly and reversed near $E_{\mathrm{K}}$, was abolished with modest levels of extracellular $\mathrm{Ba}^{2+}$ or the GIRK blocker, SCH23390, and was occluded by maximally activating GIRKs. Furthermore, the SCH23390-mediated depolarization of VMN neurons indicated that GIRKs in VMN neurons are active at rest. Tonic GIRK activation would oppose the activity of VMN neurons, presumably reducing their anorexigenic influence. This concept was supported by the observation of a lean phenotype in either mice lacking GIRK1 or GIRK2 (Pravetoni and Wickman, 2008). However, the specific GIRK subunits expressed by NPY-sensitive VMN neurons remain to be identified.

\section{Considerations of downstream effects by NPY signaling in VMN neurons}

There is a functional glutamatergic connection between the dmand $\mathrm{c}-\mathrm{VMN}$ and ARC proopiomelanocortin (POMC) neurons (Sternson et al., 2005). Although NPY inhibits VMN neurons, they are activated by leptin. Leptin induces the expression of c-fos, a marker for neuronal activation, in VMN neurons (Yokosuka et al., 1998; Elias et al., 2000) and depolarizes VMN neurons (Dhillon et al., 2006); this is consistent with our observations that leptin excites VMN neurons. Since the great majority of LepRbexpressing VMN neurons are also NPY-sensitive, one possibility is that NPY and leptin modulate the downstream outputs of dmand c-VMN neurons, onto neurons such as the ARC POMC neurons.

In this model, relatively steady central levels of leptin would produce a tonic activation of glutamatergic VMN neurons main-
SATIATED
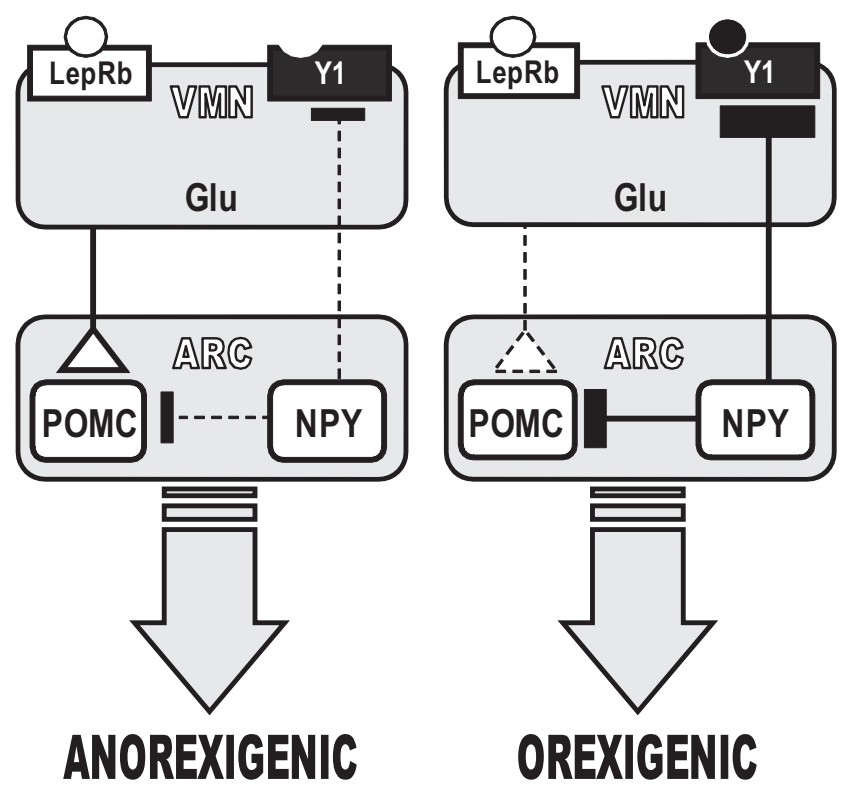

Figure 7. Schematic diagram of the network circuitry between VMN and ARC. Under satiated conditions (left), the NPY neurons in the ARC are inactive, and the tonically present leptin (O) maintains activity in glutamatergic VMN efferent neurons $(\triangle)$ that innervate ARC POMC neurons. During hunger (right), neurons in the ARC are actively releasing NPY (O) onto the VMN. The tonic effect of leptin is overcome by the robust, NPY-mediated inhibition of VMN neurons (I). This will decrease the VMN-mediated excitation of ARC POMC neurons and contribute to the net orexigenic actions of NPY.

taining a level of synaptic excitation onto ARC POMC neurons (Sternson et al., 2005). Such activity would promote the release of melanocortins that induce and maintain a state of reduced food intake and enhanced energy expenditure. When NPY neurons become active, the NPY released at the VMN activates a $Y_{1}$ mediated activation of membrane GIRKs that result in the inhibition of VMN neuronal activity and a reduction in their sensitivity to excitatory influences like leptin. This in turn will tend to reduce activity in ARC POMC neurons (Fig. 7). Furthermore, the innervation of ARC POMC neurons by the ARC NPY/ AgRP/GABA cells will also inhibit them directly via the activation of their postsynaptic $\mathrm{Y}_{1}$ and $\mathrm{GABA}_{\mathrm{A}}$ receptors (Cowley et al., 2001). Thus, activity in ARC NPY neurons would, via multiple pathways, reduce excitatory influences and enhance the inhibition of ARC POMC neurons (Cowley et al., 2001).

A subpopulation of NPY- and LepRb-expressing VMN neurons was also sensitive to glucose, which consistently inhibited these neurons at physiological concentrations (Mayer et al., 2006). Leptin receptors have been reported to be expressed in VMN GI neurons (Kang et al., 2004) and leptin signaling in the VMN modulates glucose homeostasis (Morton, 2007; Zhang et al., 2008). As with NPY, the effects of leptin on GI neurons are independent of changes in extracellular glucose concentration (Irani et al., 2008). Several ionic species have been postulated to underlie the conductance mediating the GI response, including $\mathrm{Cl}^{-}$(Song et al., 2001) and $\mathrm{K}^{+}$(Burdakov, 2007). In contrast to such previous findings, we contend that neither $\mathrm{Cl}^{-}$nor $\mathrm{K}^{+}$ alone mediate the GI response in NPY-sensitive VMN neurons. The reversal potential of the GI-mediated current $(-70 \mathrm{mV})$ was closer to the theoretical $E_{\mathrm{Cl}}(-85 \mathrm{mV})$ and the muscimolinduced $\mathrm{GABA}_{\mathrm{A}}$ receptor current $(-80 \mathrm{mV})$ than the theoretical $E_{\mathrm{K}}(-95 \mathrm{mV})$. Although additional investigation is needed, we 
suggest that a mixed conductance, possibly involving $\mathrm{Cl}^{-}$, is implicated in the GI-mediated current response. In contrast, neurons of the ventromedial ( $\mathrm{vm})-\mathrm{VMN}$, an area closely related to the facilitation of mating behaviors and that expresses androgen and/or estrogen receptors (Simerly et al., 1990), preferentially engage $\mathrm{K}^{+}$channels in their GI responses (Williams and Burdakov, 2009). It is therefore possible that dm- or c-VMN GI neurons represent a functionally different population of neurons than those of the vm-VMN.

Interestingly, the convergence of energy balance-related signals (i.e., NPY and leptin) with glucose signals occurs only on a relatively small population of LepRb-expressing $\mathrm{dm}$ - and c-VMN neurons. This suggests that, although VMN networks involved in the regulation of glucose and energy homeostasis may overlap, VMN neurons participating in both networks are relatively uncommon. Notably, the underlying connections with the leptin and glucose systems reveal the importance of NPY signaling within the VMN for the regulation of feeding behaviors.

\section{References}

Acuna-Goycolea C, Tamamaki N, Yanagawa Y, Obata K, van den Pol AN (2005) Mechanisms of neuropeptide Y, peptide YY, and pancreatic polypeptide inhibition of identified green fluorescent protein-expressing GABA neurons in the hypothalamic neuroendocrine arcuate nucleus. J Neurosci 25:7406-7419.

Balasubramanyan S, Stemkowski PL, Stebbing MJ, Smith PA (2006) Sciatic chronic constriction injury produces cell-type-specific changes in the electrophysiological properties of rat substantia gelatinosa neurons. J Neurophysiol 96:579-590.

Beck B (2006) Neuropeptide Y in normal eating and in genetic and dietaryinduced obesity. Philos Trans R Soc Lond B Biol Sci 361:1159-1185.

Bouali SM, Fournier A, St-Pierre S, Jolicoeur FB (1995) Effects of NPY and NPY2-36 on body temperature and food intake following administration into hypothalamic nuclei. Brain Res Bull 36:131-135.

Broberger C, Johansen J, Johansson C, Schalling M, Hökfelt T (1998) The neuropeptide $\mathrm{Y} /$ agouti gene-related protein (AGRP) brain circuitry in normal, anorectic, and monosodium glutamate-treated mice. Proc Natl Acad Sci U S A 95:15043-15048.

Burdakov D (2007) $\mathrm{K}^{+}$channels stimulated by glucose: a new energysensing pathway. Pflugers Arch 454:19-27.

Canteras NS, Simerly RB, Swanson LW (1994) Organization of projections from the ventromedial nucleus of the hypothalamus: a Phaseolus vulgarisleucoagglutinin study in the rat. J Comp Neurol 348:41-79.

Chee MJ, Colmers WF (2008) Y eat? Nutrition 24:869-877.

Clark JT, Kalra PS, Crowley WR, Kalra SP (1984) Neuropeptide Y and human pancreatic polypeptide stimulate feeding behavior in rats. Endocrinology 115:427-429.

Collin M, Bäckberg M, Ovesjö ML, Fisone G, Edwards RH, Fujiyama F, Meister B (2003) Plasma membrane and vesicular glutamate transporter mRNAs/proteins in hypothalamic neurons that regulate body weight. Eur J Neurosci 18:1265-1278.

Cowley MA, Smart JL, Rubinstein M, Cerdán MG, Diano S, Horvath TL, Cone RD, Low MJ (2001) Leptin activates anorexigenic POMC neurons through a neural network in the arcuate nucleus. Nature 411:480-484.

Cowley MA, Smith RG, Diano S, Tschöp M, Pronchuk N, Grove KL, Strasburger CJ, Bidlingmaier M, Esterman M, Heiman ML, Garcia-Segura LM, Nillni EA, Mendez P, Low MJ, Sotonyi P, Friedman JM, Liu H, Pinto S, Colmers WF, Cone RD, et al (2003) The distribution and mechanism of action of ghrelin in the CNS demonstrates a novel hypothalamic circuit regulating energy homeostasis. Neuron 37:649-661.

Davidowa H, Li Y, Plagemann A (2002) Differential response to NPY of $\mathrm{PVH}$ and dopamine-responsive VMH neurons in overweight rats. Neuroreport 13:1523-1527.

Dhillon H, Zigman JM, Ye C, Lee CE, McGovern RA, Tang V, Kenny CD, Christiansen LM, White RD, Edelstein EA, Coppari R, Balthasar N, Cowley MA, Chua S Jr, Elmquist JK, Lowell BB (2006) Leptin directly activates SF1 neurons in the $\mathrm{VMH}$, and this action by leptin is required for normal bodyweight homeostasis. Neuron 49:191-203.

El Bahh B, Balosso S, Hamilton T, Herzog H, Beck-Sickinger AG, Sperk G, Gehlert DR, Vezzani A, Colmers WF (2005) The anti-epileptic actions of neuropeptide $\mathrm{Y}$ in the hippocampus are mediated by $\mathrm{Y}$ and not $\mathrm{Y}$ receptors. Eur J Neurosci 22:1417-1430.

Elias CF, Kelly JF, Lee CE, Ahima RS, Drucker DJ, Saper CB, Elmquist JK (2000) Chemical characterization of leptin-activated neurons in the rat brain. J Comp Neurol 423:261-281.

Eva C, Serra M, Mele P, Panzica G, Oberto A (2006) Physiology and gene regulation of the brain NPY Y1 receptor. Front Neuroendocrinol 27:308-339.

Fetissov SO, Kuteeva E, Hökfelt T (2003) Directional cues for arcuate NPY projections are present in the adult brain. Exp Neurol 183:116-123.

Fu LY, van den Pol AN (2008) Agouti-related peptide and MC3/4 receptor agonists both inhibit excitatory hypothalamic ventromedial nucleus neurons. J Neurosci 28:5433-5449.

Fu LY, Acuna-Goycolea C, van den Pol AN (2004) Neuropeptide Y inhibits hypocretin/orexin neurons by multiple presynaptic and postsynaptic mechanisms: tonic depression of the hypothalamic arousal system. J Neurosci 24:8741-8751.

Haskell-Luevano C, Chen P, Li C, Chang K, Smith MS, Cameron JL, Cone RD (1999) Characterization of the neuroanatomical distribution of agoutirelated protein immunoreactivity in the rhesus monkey and the rat. Endocrinology 140:1408-1415.

Hetherington AW, Ranson SW (1940) Hypothalamic lesions and adiposity in the rat. Anat Rec 78:149-172.

Irani BG, Le Foll C, Dunn-Meynell A, Levin BE (2008) Effects of leptin on rat ventromedial hypothalamic neurons. Endocrinology 149:5146-5154.

Jolicoeur FB, Bouali SM, Fournier A, St-Pierre S (1995) Mapping of hypothalamic sites involved in the effects of NPY on body temperature and food intake. Brain Res Bull 36:125-129.

Kalra SP, Dube MG, Fournier A, Kalra PS (1991) Structure-function analysis of stimulation of food intake by neuropeptide Y: effects of receptor agonists. Physiol Behav 50:5-9.

Kang L, Routh VH, Kuzhikandathil EV, Gaspers LD, Levin BE (2004) Physiological and molecular characteristics of rat hypothalamic ventromedial nucleus glucosensing neurons. Diabetes 53:549-559.

Karschin C, Dissmann E, Stühmer W, Karschin A (1996) IRK(1-3) and GIRK(1-4) inwardly rectifying $\mathrm{K}^{+}$channel mRNAs are differentially expressed in the adult rat brain. J Neurosci 16:3559-3570.

King BM (2006) The rise, fall, and resurrection of the ventromedial hypothalamus in the regulation of feeding behavior and body weight. Physiol Behav 87:221-244.

Kishi T, Aschkenasi CJ, Choi BJ, Lopez ME, Lee CE, Liu H, Hollenberg AN, Friedman JM, Elmquist JK (2005) Neuropeptide Y Y1 receptor mRNA in rodent brain: distribution and colocalization with melanocortin-4 receptor. J Comp Neurol 482:217-243.

Kopp J, Xu ZQ, Zhang X, Pedrazzini T, Herzog H, Kresse A, Wong H, Walsh JH, Hökfelt T (2002) Expression of the neuropeptide Y Y1 receptor in the CNS of rat and of wild-type and Y1 receptor knock-out mice. Focus on immunohistochemical localization. Neuroscience 111:443-532.

Kumarnsit E, Johnstone LE, Leng G (2003) Actions of neuropeptide Y and growth hormone secretagogues in the arcuate nucleus and ventromedial hypothalamic nucleus. Eur J Neurosci 17:937-944.

Kuzhikandathil EV, Oxford GS (2002) Classic D1 dopamine receptor antagonist $R$-(+)-7-chloro-8-hydroxy-3-methyl-1-phenyl-2,3,4,5-tetrahydro-1 H-3-benzazepine hydrochloride (SCH23390) directly inhibits $\mathrm{G}$ protein-coupled inwardly rectifying potassium channels. Mol Pharmacol 62:119-126.

Leshan RL, Bjornholm M, Munzberg H, Myers MG Jr (2006) Leptin receptor signaling and action in the central nervous system. Obesity (Silver Spring) 14:208S-212S.

Leshan RL, Louis GW, Jo YH, Rhodes CJ, Münzberg H, Myers MG Jr (2009) Direct innervation of GnRH neurons by metabolism- and sexual odorant-sensing leptin receptor neurons in the hypothalamic ventral premammillary nucleus. J Neurosci 29:3138-3147.

Lopez-Valpuesta FJ, Nyce JW, Griffin-Biggs TA, Ice JC, Myers RD (1996) Antisense to NPY-Y1 demonstrates that Y1 receptors in the hypothalamus underlie NPY hypothermia and feeding in rats. Proc Biol Sci 263:881-886

Lu VB, Moran TD, Balasubramanyan S, Alier KA, Dryden WF, Colmers WF, Smith PA (2006) Substantia gelatinosa neurons in defined-medium organotypic slice culture are similar to those in acute slices from young adult rats. Pain 121:261-275.

Majdic G, Young M, Gomez-Sanchez E, Anderson P, Szczepaniak LS, Dobbins RL, McGarry JD, Parker KL (2002) Knockout mice lacking ste- 
roidogenic factor are a novel genetic model of hypothalamic obesity. Endocrinology 143:607-614.

Mao X, Fujiwara Y, Orkin SH (1999) Improved reporter strain for monitoring cre recombinase-mediated DNA excisions in mice. Proc Natl Acad Sci U S A 96:5037-5042.

Mayer CH, Fink H, Rex A, Voigt JP (2006) Changes in extracellular hypothalamic glucose in relation to feeding. Eur J Neurosci 24:1695-1701.

Melnick I, Pronchuk N, Cowley MA, Grove KL, Colmers WF (2007) Developmental switch in neuropeptide $\mathrm{Y}$ and melanocortin effects in the paraventricular nucleus of the hypothalamus. Neuron 56:1103-1115.

Morin SM, Gehlert DR (2006) Distribution of NPY Y5-like immunoreactivity in the rat brain. J Mol Neurosci 29:109-114.

Morton GJ (2007) Hypothalamic leptin regulation of energy homeostasis and glucose metabolism. J Physiol 583:437-443.

Perry CA, Pravetoni M, Teske JA, Aguado C, Erickson DJ, Medrano JF, Luján R, Kotz CM, Wickman K (2008) Predisposition to late-onset obesity in GIRK4 knockout mice. Proc Natl Acad Sci U S A 105:8148-8153.

Pravetoni M, Wickman K (2008) Behavioral characterization of mice lacking GIRK/Kir3 channel subunits. Genes Brain Behav 7:523-531.

Pronchuk N, Beck-Sickinger AG, Colmers WF (2002) Multiple NPY receptors inhibit $\mathrm{GABA}_{\mathrm{A}}$ synaptic responses of rat medial parvocellular effector neurons in the hypothalamic paraventricular nucleus. Endocrinology 143:535-543.

Roseberry AG, Liu H, Jackson AC, Cai X, Friedman JM (2004) Neuropeptide Y-mediated inhibition of proopiomelanocortin neurons in the arcuate nucleus shows enhanced desensitization in ob/ob mice. Neuron 41:711-722.

Routh VH (2003) Glucosensing neurons in the ventromedial hypothalamic nucleus (VMN) and hypoglycemia-associated autonomic failure (HAAF). Diabetes Metab Res Rev 19:348-356.

Saper CB, Swanson LW, Cowan WM (1976) The efferent connections of the ventromedial nucleus of the hypothalamus of the rat. J Comp Neurol 169:409-442.

Simerly RB, Chang C, Muramatsu M, Swanson LW (1990) Distribution of androgen and estrogen receptor mRNA-containing cells in the rat brain: an in situ hybridization study. J Comp Neurol 294:76-95.

Slesinger PA (2001) Ion selectivity filter regulates local anesthetic inhibition of G-protein-gated inwardly rectifying $\mathrm{K}^{+}$channels. Biophys J 80:707718.

Sodickson DL, Bean BP (1996) $\mathrm{GABA}_{\mathrm{B}}$ receptor-activated inwardly rectifying potassium current in dissociated hippocampal CA3 neurons. J Neurosci 16:6374-6385.

Song Z, Levin BE, McArdle JJ, Bakhos N, Routh VH (2001) Convergence of pre-and postsynaptic influences on glucosensing neurons in the ventromedial hypothalamic nucleus. Diabetes 50:2673-2681.

Stanić D, Brumovsky P, Fetissov S, Shuster S, Herzog H, Hökfelt T (2006) Characterization of neuropeptide $\mathrm{Y} 2$ receptor protein expression in the mouse brain. I. Distribution in cell bodies and nerve terminals. J Comp Neurol 499:357-390.

Stanley BG, Magdalin W, Seirafi A, Thomas WJ, Leibowitz SF (1993) The perifornical area: the major focus of (a) patchily distributed hypothalamic neuropeptide Y-sensitive feeding system(s). Brain Res 604:304-317.

Sternson SM, Shepherd GM, Friedman JM (2005) Topographic mapping of $\mathrm{VMH} \rightarrow$ arcuate nucleus microcircuits and their reorganization by fasting. Nat Neurosci 8:1356-1363.

Takano M, Ashcroft FM (1996) The $\mathrm{Ba}^{2+}$ block of the ATP-sensitive $\mathrm{K}^{+}$ current of mouse pancreatic beta-cells. Pflugers Arch 431:625-631.

Tu B, Timofeeva O, Jiao Y, Nadler JV (2005) Spontaneous release of neuropeptide $\mathrm{Y}$ tonically inhibits recurrent mossy fiber synaptic transmission in epileptic brain. J Neurosci 25:1718-1729.

Williams JT, Colmers WF, Pan ZZ (1988) Voltage- and ligand-activated inwardly rectifying currents in dorsal raphe neurons in vitro. J Neurosci 8:3499-3506.

Williams RH, Burdakov D (2009) Silencing of ventromedial hypothalamic neurons by glucose-stimulated $\mathrm{K}^{+}$currents. Pflugers Arch 458:777-783.

Yokosuka M, Xu B, Pu S, Kalra PS, Kalra SP (1998) Neural substrates for leptin and neuropeptide Y (NPY) interaction: hypothalamic sites associated with inhibition of NPY-induced food intake. Physiol Behav 64:331-338.

Zhang R, Dhillon H, Yin H, Yoshimura A, Lowell BB, Maratos-Flier E, Flier JS (2008) Selective inactivation of Socs3 in SF1 neurons improves glucose homeostasis without affecting body weight. Endocrinology 149:56545661. 